\title{
Crystal structure of 6-SST/6-SFT from Pachysandra terminalis, a plant fructan biosynthesizing enzyme in complex with its acceptor substrate 6-kestose
}

\author{
Willem Lammens ${ }^{1,2}$, Katrien Le Roy ${ }^{1}$, Shuguang Yuan ${ }^{1,3}$, Rudy Vergauwen ${ }^{1}$, Anja Rabijns ${ }^{2}$, André Van Laere ${ }^{1}$, \\ Sergei V. Strelkov ${ }^{2}$ and Wim Van den Ende ${ }^{1, *}$ \\ ${ }^{1}$ Biology Department, Laboratory for Molecular Plant Physiology, Katholieke Universiteit Leuven, Kasteelpark \\ Arenberg 31, Box 2434, B-3001 Heverlee, Belgium, \\ ${ }^{2}$ Department of Pharmaceutical Sciences, Laboratory for Biocrystallography, Katholieke Universiteit Leuven, \\ Herestraat 49, Box 822, B-3000 Leuven, Belgium, and \\ ${ }^{3}$ International Institute of Molecular and Cell Biology in Warsaw, 4 Ks. Trojdena Street, 02-109 Warsaw, Poland
}

Received 4 November 2011; accepted 15 November 2011; published online 10 January 2012.

*For correspondence (fax +32 163219 67; e-mail wim.vandenende@bio.kuleuven.be).

\begin{abstract}
SUMMARY
Fructans play important roles as reserve carbohydrates and stress protectants in plants, and additionally serve as prebiotics with emerging antioxidant properties. Various fructan types are synthesized by an array of plant fructosyltransferases belonging to family 32 of the glycoside hydrolases (GH32), clustering together with GH68 in Clan-J. Here, the 3D structure of a plant fructosyltransferase from a native source, the Pachysandra terminalis 6-SST/6-SFT (Pt6-SST/6-SFT), is reported. In addition to its 1-SST (1-kestose-forming) and hydrolytic side activities, the enzyme uses sucrose to create graminan- and levan-type fructans, which are probably associated with cold tolerance in this species. Furthermore, a Pt6-SST/6-SFT complex with 6-kestose was generated, representing a genuine acceptor binding modus at the $+1,+2$ and +3 subsites in the active site. The enzyme shows a unique configuration in the vicinity of its active site, including a unique $D / Q$ couple located at the +1 subsite that plays a dual role in donor and acceptor substrate binding. Furthermore, it shows a unique orientation of some hydrophobic residues, probably contributing to its specific functionality. A model is presented showing formation of a $\beta(2-6)$ fructosyl linkage on 6-kestose to create 6,6-nystose, a mechanism that differs from the creation of a $\beta(2-1)$ fructosyl linkage on sucrose to produce 1-kestose. The structures shed light on the evolution of plant fructosyltransferases from their vacuolar invertase ancestors, and contribute to further understanding of the complex structure-function relationships within plant GH32 members.
\end{abstract}

Keywords: 1-kestose, 6-kestose, fructan, fructosyltransferase, glycoside hydrolase family 32, Pachysandra terminalis, sucrose.

\section{INTRODUCTION}

Fructans, linear or branched oligo- or polymers of fructose (Fru), often containing one (terminal) glucose (GIc) molecule, are widespread carbohydrates that occur in prokaryotes, fungi, algae and in $15 \%$ of flowering plants (Hendry, 1993). Different fructan types can be discerned: inulin-type [ $\beta(2-1)$ Fru-Fru linkages], levan-type [ $\beta(2-6)$ linkages], graminan-type (mixed linkages), neo-inulin-type and neolevan-type fructans (Vijn and Smeekens, 1999; Vergauwen et al., 2003; Van den Ende et al., 2005, 2006). In addition to their prominent role as vacuolar storage carbohydrates in plants, fructans may protect plants against freezing and drought stress (Valluru and Van den Ende, 2008), probably by membrane stabilization (Vereyken et al., 2003) and/or by their putative ROS-scavenging capacity as observed for other saccharides (Nishizawa et al., 2008; Van den Ende and Valluru, 2009; Stoyanova et al., 2011).

Even more importantly, inulins and other types of fructans are emerging as powerful and rather cheap health-promoting food and feed supplements (Stoyanova et al., 2011). In addition to their prebiotic action, they may counteract oxidative stress via direct (ROS-scavenging) or more indirect mechanisms, preventing the development of ROS-related diseases such as colon cancer and other diseases (Van den Ende et al., 2011b). Fructans with a higher degree of 
H1

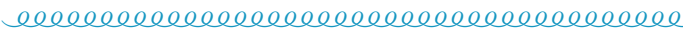

Pt 6-SST/6-SFT

At cwINV1

Ci 1-FEHIIa

Tm beta-fruct

Aa exo-inul

So invertase

Bl beta-fruct

Aj FT

At cwINV1

Ci 1-FEHIIa

Tm beta-fruct

Aa exo-inul

So invertase

Bl beta-fruct

Aj FT

Pt 6-SST/6-SFT

At cwINV1

Ci 1-FEHIIa

Tm beta-fruct

Aa exo-inul

So invertase

Bl beta-fruct

Aj FT

Pt 6-SST/6-SFT

At cwINV1

Ci 1-FEHIIa

Tm beta-fruct

Aa exo-inul

So invertase

BI beta-fruct

Aj FT

Pt 6-SST/6-SFT

At CWINV1

Ci 1-FEHIIa

Tm beta-fruct

Aa exo-inul

So invertase

Bl beta-fruct

Aj FT

Pt 6-SST/6-SFT

At cwINV1

Ci 1-FEHIIa

Tm beta-fruct

Aa exo-inul

So invertase

Bl beta-fruct

Aj FT

Pt 6-SST/6-SFT

At cwINV1

Ci 1-FEHIIa

$\mathrm{Tm}$ beta-fruct

Aa exo-inul

So invertase

Aj FT
Pt 6-SST/6-SFT

Bl beta-fruct

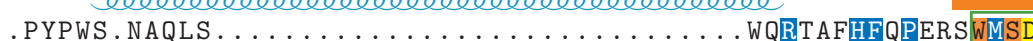

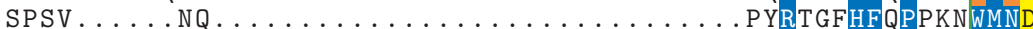

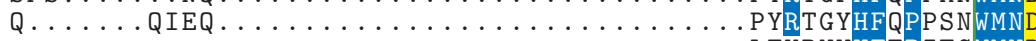

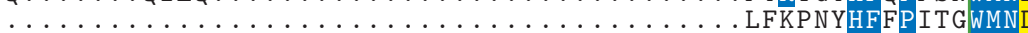

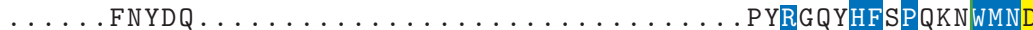
MTDF . . . . TPETPVLTPIRDHAAELAKAEAGVAEMAAKRNNRWYPKYHIASNGGWIND YHLDTT.APPPTNLSTLPNNTLFH . . . . . . . . . . WRPRAHILPAEGQIGD

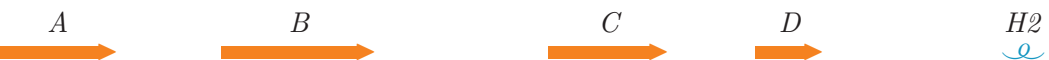
SIDLSV.DTSE . . . . . . . . . . . . . . . . . . . YNRPLIHFTPEKGWMND

$\overrightarrow{P D G P I F Y} \ldots$.K. . GWYHFFYQYNPDNPVWG. NNTWGHTVSRDLIHWLYLP . . . . LALAADQ PNGPMIY . . K. . GIYHLFYQWNPKGAVWG. NIVWAHSTSTDLINWDPHP . . . PAIFPSA PNGPMLY . . . . GVYHFFYQYNPYAA TFGDVI I IGHAVSYDLVNWIHLD . . . PAIYPTQ
PNGLIFW . . K. . GKYHMFYQYNPRKPEWG. NI CWGHAVSDDLVHWRHLP. . . VALYPDD PNGLLYH . . N. . GTYHLFFQYNPGGIEWG. NI SWGHAISEDLTHWEEKP. . . . VALLARG PNGLFYD . . KTAKLWHLYFQYNPNATAWGQPLYWGHATSNDLVHWDEHE . . . IAIGPEH PNGLCFY . . K. . GRWHVFYQLHPYGTQWG. PMHWGHVSSTDMLNWKREP . . . . IMFAPSL PCAHYTDPST . GLFHVGFLHD . . . . . . . DGIAGATTANLATYTDTSDNGSFL IQPGG

H2 eleee $A$

$B$

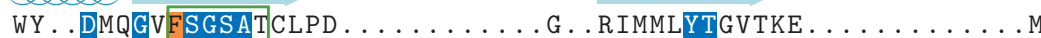

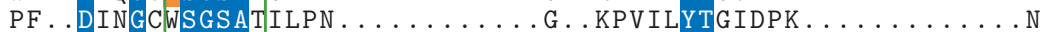

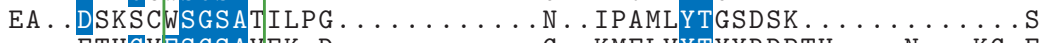
$\ldots \ldots$ ETHGVFSGSAVEK.D . . . . . . . . . . KMFLVYTYYRDPTH . . N . . KG.E FGSDVTEMYFSGSAVAD . VNNTSGFGKDGKT . . . PLVAMYTSYYPVAQTLPSGQTVQ . . E $\ldots .$. DNEGIF SGSIVVD . HNNTSGFFNSS IDPNQRIVA IYTNN IP . . . . . . . . . . . D EQ. .EKDGVFSGSAVIDDN . ............ . DLRFYYTGHRWANG . . . HDNTGG. D KN . DPVAVEDGAVIPV.GVN . . . . . . . . . TPTLLYTSVSFLPIHWSIP . . YTRG

\section{$C$}

\section{$D$}

$A$

VEMLSLAYPADLSDPLLVEWVKY . PGNPILSA . . . . . P . . PG . VSPTEFRDASTGWY . . . QQVQN IAEPKNLSDPYLREWKKS . PLNPLMAP . . . . . DAVNG . INASSFRDPT TAWL . . . RQVQDLAWPKNLSDPFLREWVKH . PKNPLITP . . . . . . . EG. VKDDCFRDPSTAWL . . .KETQCVVMS . . E. N . GLDFVKY . DGNPVISK . . . . . . PEE. GT . HAFRDPKVNRS . . DQQSQS IAYS . . L.DD . GLTWTTYDA ANPVIPNPPSPYEAE . . . . . . QNFRDPFVFWHDE .NQTQDIAFS . . L.DG.GYTFTKY. ENNPVIDV . . . . . . . . . . . NQFRDPKVFWHED .WQVQMTALPD. N.DE . LTSATKQ . . GMIIDC . . . . P. TDK . VD . HHYRDPKVWKT . . . SETQSLAVA . RDG. GRRFDKL . DQGPVIAD . . . . . H. PFAVDV . TAFRDPFVFRSAR

A

. VSN.

\section{$B$}

$C$

...GTWRIAIGAKYN TTGIAMVYET...K. . DF

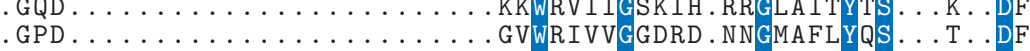
. N . . . . . . . . . . . . . . . GEWRMVLGSGKDEKIGRVLLYTS . . D . . DL

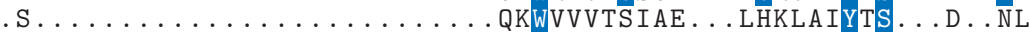
. S . . . . . . . . . . . . . . . NQWIMVVSKSQ . . EYKIQIFGS . . A . NL . G . . . . . . . . . . . . . . . . DTWYMTFGVSSADKRGQMWLFSS . . K . . DM LDVLLSLDEEVARNETAVQQA VDGWTEKNAPWYVAVSGGVHGVGPAQFLYRQNGGNASEF
$D 1$
D2
$A$

KSFKLLEELLH.AV ..P.D . ............ TGLWECVDLYPV . . . . . STTGEKGLET LKWEKSPEPLH . YD . D. G . . . . . . . . . SGMWECPDFFPV . . . . . TRFGSNGVET

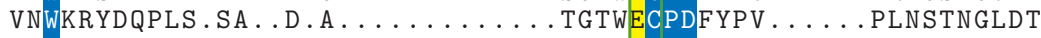
FHWKYE.GAIF.ED . E. . . . . . . . . . TKEIECPDLVRI . . . . . . . . . . . KDWKLV.SEFGPYN . A.Q. . . . . . . . . GGVWECPGLVKLPLDSGNS . . . . . .

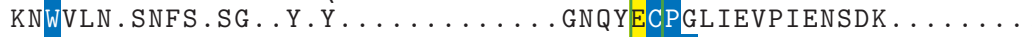
VRWEYE.RVLF.QHPDP . D . . . . . . . . . VFMLECPDFSPI . . . . KDKDGN . . . QYWEYL. GEWW. QE. . ATNSSWGDEGTWAGRWGFNFETGNVLFL . . . . . TEEGHDPQT .

\section{$B$}

C

SVNGP . . KVKHVLKASIDE . . . . . . . . . . QRRYYA IGTYDLGT . . . . .

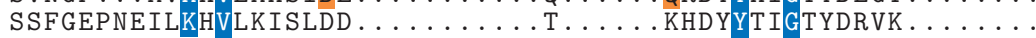
SVYGG . . SVRHVMKAGF . . . . . . . . . E . . . . GHDWYT IGTYSPDR . . . . . . . . . . $\ldots \ldots \ldots$ ERDILIYSITS . . . . . . . . . . . . . . NSVLFSMGELK . E . . . . . . $\ldots \ldots$. . . . TKWVITSGLNPG . . . . . . . . GPPGTVGSGTQYFVGEFDG. T . . . . . .

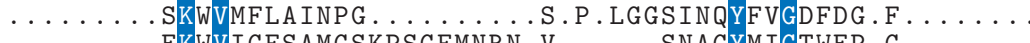
$\ldots \ldots \ldots$ EKWVIGFSAMGSKP SGFMNRN . V . . . . . . SNAGYMIGTWEP. G . . . . . . . . . . 
polymerization (DP) and branched-type fructans (e.g. graminans derived from cereals) are expected to be processed more slowly throughout the colon by bacterial fructandegrading enzymes, providing better 'protection' over the whole gut system, and contributing to more efficient disease prevention (Van den Ende et al., 2011b).

Synthesis of plant fructans requires a variety of fructan biosynthetic enzymes or fructosyltransferases (FTs), each with their own preferential donor and acceptor substrates. S-type FTs include sucrose:sucrose 1-fructosyltransferases (1-SST; E.C. 2.4.1.99) and sucrose:fructan 6-fructosyltransferases (6-SFT; E.C. 2.4.1.10). These enzymes use sucrose (Suc) as exclusive fructosyl donor. F-type FTs include fructan:fructan 1-fructosyltransferases (1-FFT; E.C. 2.4.1.100) and fructan:fructan $6^{\mathrm{G}}$-fructosyltransferases $\left(6^{\mathrm{G}}-\mathrm{FFT}\right.$; E.C. 2.4.1.243). They use fructans as fructosyl donor (Schroeven et al., 2009; Van den Ende et al., 2009). Inulin biosynthesis in dicots requires the combined action of 1-SST and 1-FFT (Edelman and Jefford, 1968; Van den Ende and Van Laere, 2007). At least three FTs are required to produce the various fructan types in monocots (Prud'homme et al., 2007; Yoshida et al., 2007). 6-SFT is a key enzyme in monocot fructan biosynthesis. It preferentially transfers the fructosyl unit of Suc to a wide variety of acceptors such as 1-kestose (Duchateau et al., 1995), 6-kestose (Tamura et al., 2009) and $6^{\mathrm{G}}$-kestotriose (Lasseur et al., 2011). The unexpected presence of graminan- and levan-type fructans in the eudicot species Pachysandra terminalis (Japanese spurge) led to isolation of a specific Pt6-SST/6-SFT (Van den Ende et al., 2011a).

Plant FTs, acid invertases, inulinases, levanases, exoinulinases and fructan exohydrolases (FEHs) are members of glycoside hydrolase family 32 (GH32) (http://www.cazy.org). This family shows a common fold with the associated GH68 family. Together they form Clan-J of the glycoside hydrolases. All Clan-J enzymes have a $\beta$-propeller catalytic domain. GH32 members contain an additional $\beta$-sandwich module. This module helps to stabilize the catalytic domain (Altenbach et al., 2004), may play a key role in substrate specificity (Alvaro-Benito et al., 2010) and may interact with specific protein inhibitors (Hothorn et al., 2010). However, it has been established that substrate specificity also greatly depends on particular amino acids in the vicinity of the active site (Ritsema et al., 2006; Altenbach et al., 2009; Van den Ende et al., 2009).

To date, several GH32 crystal structures have been determined, as reviewed by Lammens et al. (2009). Figure 1 shows a primary sequence alignment of the determined structures. Recently, three extra crystal structures in the GH32 family have been elucidated: a $\beta$-fructofuranosidase from Schwanniomyces occidentalis (Protein Data Bank ID 3KF5) (Alvaro-Benito et al., 2010), a fructosyltransferase from Aspergillus japonicus (AjFT; Protein Data Bank ID 3LF7) (Chuankhayan et al., 2010) and a $\beta$-fructofuranosidase from Bifidobacterium longum (Protein Data Bank ID 3PIG) (Bujacz et al., 2011). Furthermore, the complex structure of a plant invertase with its proteinaceous inhibitor was determined (Hothorn et al., 2010).

So far, only two plant crystal structures have been determined: a cell-wall invertase from Arabidopsis thaliana (AtcwINV1) and an FEH from Cichorium intybus (Ci1FEHIla); both are hydrolases that preferentially degrade sucrose and fructans, respectively (Lammens et al., 2009). However, no crystal structure of any plant FT was available. The elucidation of such plant FT 3D structure is therefore an important milestone in fructan research. In particular, food industries are eagerly searching for superior prebiotics and antioxidants. In the future, it may be possible to use naturally occurring and improved fructanbranching enzymes (such as 6-SFTs) to produce higher-DP and branched-type fructans with dual characteristics as prebiotics and antioxidants (Van den Ende et al., 2011b; and references therein). Recent findings show that ingestion of different fructan types leads to specific shifts in the gut microbiome (Sonnenburg et al., 2010). By varying fructan ratios in individual diets, it is possible to specifically manipulate the microbiome of an individual with a specific genotype. This will pave the way to personalized preventive medicine. To drive this evolution, obtaining the 3D structure information of a plant FT would be very helpful. Here, we present a $1.7 \AA$ crystal structure of the Pt6-SST/6-SFT enzyme that has been purified from a native source. Furthermore, we generated complexes with 1kestose and 6-kestose trisaccharides.

\section{RESULTS}

\section{Overall structure of Pt6-SST/6-SFT and its complexes with 1-kestose and 6-kestose}

Diffraction data for the apo crystal of Pt6-SST/6-SFT were collected up to a resolution of $1.7 \AA$, whereas crystals soaked with 1-kestose and 6-kestose diffracted to a resolution of $2.9 \AA$ (Table 1). The crystals belong to the

Figure 1. Multiple sequence alignment of the GH32 family enzymes based on superimposing their 3D structures using STRAP (Gille and Frommel, 2001). The sequences are Pachysandra terminalis 6-SST/6-SFT (Pt 6-SST/6-SFT; Protein Data Bank ID 3UGF), Arabidopsis thaliana cell-wall invertase 1 (At cwINV1; Protein Data Bank ID 2AC1), Cichorium intybus fructan 1-exohydrolase lla (Ci 1-FEHIla; Protein Data Bank ID 1ST8), Thermotoga maritima $\beta$-fructosidase (Tm beta-fruct; Protein Data Bank ID 1UYP), Aspergillus awamori exo-inulinase (Aa exo-inul; Protein Data Bank ID 1Y9M), Schwanniomyces occidentalis invertase (So invertase; Protein Data Bank ID 3KF5); Bifidobacterium longum $\beta$-fructofuranosidase (BI beta-fruct; Protein Data Bank ID 3PIG) and Aspergillus japonicus fructosyltransferase (Aj FT; Protein Data Bank ID 3LF7). Conserved motifs are boxed in green. The catalytic triad is indicated in yellow. Important residues in Pt6-SST/6-SFT are indicated in orange. Secondary structures assignments are shown for Pt6-SST/6-SFT as calculated by PDBsum (http://www.ebi.ac.uk/pdbsum) (Laskowski, 2001). The image was created using $T_{E} X$ shade (Beitz, 2000). 
Pt 6-SST/6-SFT

At cwINV1

Ci 1-FEHIIa

Tm beta-fruct

Aa exo-inul

So invertase

Bl beta-fruct

Aj FT

Pt 6-SST/6-SFT

At cwINV1

Ci 1-FEHIIa

Tm beta-fruct

Aa exo-inul

So invertase

Bl beta-fruct

Aj FT

Pt 6-SST/6-SFT

At cwINV1

Ci 1-FEHIIa

Tm beta-fruct

$\mathrm{Aa}$ exo-inul

So invertase

Bl beta-fruct

Aj FT

Pt 6-SST/6-SFT At cwINV1

Ci 1-FEHIIa

Tm beta-fruct

Aa exo-inul

So invertase

Bl beta-fruct

Aj FT

Pt 6-SST/6-SFT

At cwINV1

Ci 1-FEHIIa

Tm beta-fruct

Aa exo-inul

So invertase

Bl beta-fruct

Aj FT

Pt 6-SST/6-SFT

At cwINV1

$\mathrm{Ci}$ 1-FEHIIa

Tm beta-fruct

Aa exo-inul

So invertase

Bl beta-fruct

Aj FT

Pt 6-SST/6-SFT

At cwINV1

Ci 1-FEHIIa

Tm beta-fruct

Aa exo-inul

So invertase

Bl beta-fruct

Aj FT

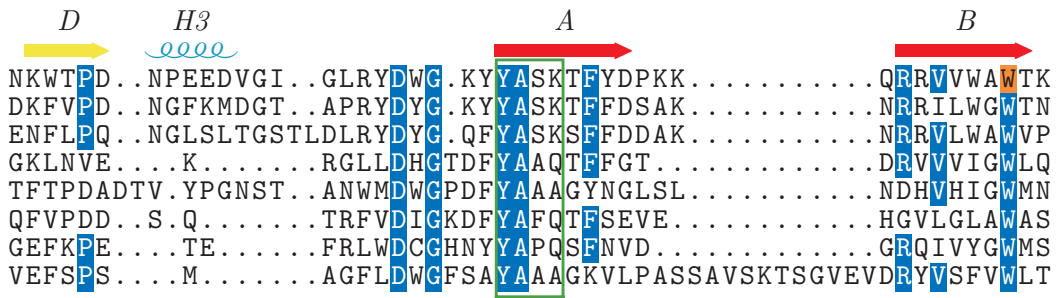

\section{$\mathrm{H}_{4}$}

$\stackrel{C 1}{\longrightarrow}$

$C^{2}$

E. LDSEVADREKGWANVQTIPRTVLT

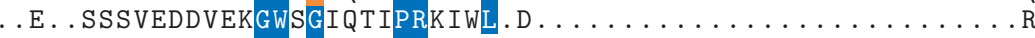
. E . TDSQADDIEKGWAGLQSFPRALWI.D . . . . . . . . . .

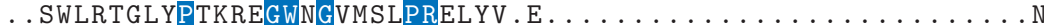

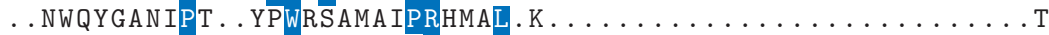
.NWQYADQVPT . NPWRSSTSLARNYTL.R . $\ldots \ldots \ldots \ldots \ldots \ldots$

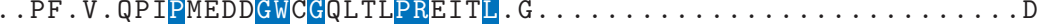
GDQYEQADGFPT AQQGWTGSLLLPRELKVQTVENVVDNEL VREEGVSWVVGESDNQTATL

H5 KT . . . . . GTNVLLWPVEEV.ESLR. L . SS . KEFSKVKAGAGS . I . . . VPLDV.G
.S . . . . . GKQLIQWPVREV.ERLR. TK.QV.KNLRNKVLKSGS . . R . . LEVYG.V . S . . . . . . GKQLIQWPVRE . ERLR.TK.QV.KNLRNKVLKSGS . . R . . . LEVYG.V ....... NE. LKVKPVDEL . LALR.KR.KV. FETA.K. S . . . . . G . . . TFLLD.V IG . . . . SKAT. LVQQPQ.EA. WSSI.SNKRPIYSRTFKTLSEGS . . T . . . NTTTT . . VHTNAETKQLT. LIQNPV. LP.DSIN.VV.DK. LKKKNVKLTNKK . . P . . . IKTNFKG D ........GD . VVTAPVAEM . EGLR. ED . TL. DHGS . V.T . . . . . LDMDGEQIIA . D ........RT.LGITIARETKAALLANG.SV. TAEE. D. RTLQTAAVV . . . PFAQS.P

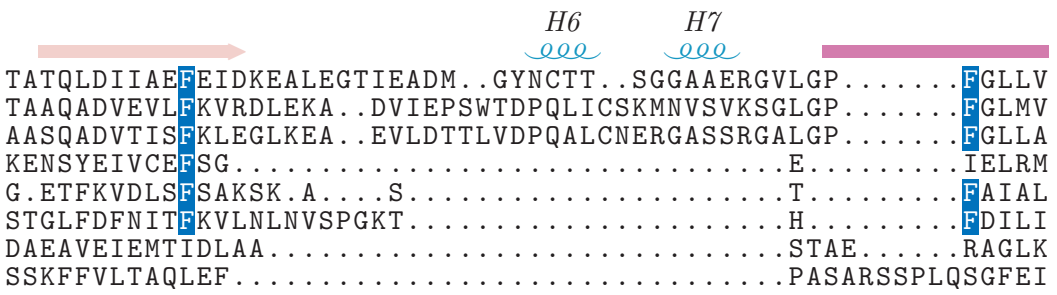

S.ATE . . . NLSEQTP.VYFYIAKGTD.G.NFKTFFCLDESRSSK . ASD . . . . . . . . SK L. ASK . . . . NLEEYTS . VYFRIFKARQNSNKYVVLMCSDQSRSSL . KED . . . N . . . . . DK M. ASK . . . . DLKEQSA. IFFRVFQNQL.G.RYSVLMCSDLSRSTV.RSN . . . I . . . . DT . . GN . . . . E. SEEVV. ITKSR . . . . . . . . D.ELIVDTTRSG . . . . . . . . . . . . GG . RASA . NF. TEQTL.VGYDFAK . . . . . Q. QIFLDRTHSG . DV . . . SF.DETFA . NSQELNSS. VDSIK. IGFDSSQ ......... S. SFYIDRHIPN . VE . ...FPRKQFFT IHAT . . . EDGAYTYVAYDGQI . . . . . . G. RVVVDRQAMA . N . . . G . . . . DR .. LAS . . . E. LERTA. IYYQFSN . . . . . E. ELVVDRSQTSAAAPTNPGLD . . . . SF

QVKGFTV ...PV ..........DGE......KFTMRLLVDHS IVESFAQGGR. SCITSR TTYGAFV ...DI . . . . . . . NPH.Q. . . . PLSLRALIDHSVVESFGGKGR . ACITSR TSYGAFV ... DI . . . . . . . . DPRSE . . . . . EISLRNLIDHSI IESFGAGGK. TCITSR EVRKSTV . . . ED . . . . . . . . . . . . . TNRIRAFLDSCSVEFFFND.S. IAFSFR SVYHGPL . . TP . . . . . . . . . . . ST . . . GVVKLSIFVDRSSVEVFGGQ. GETTLTAQ DKLAAYL . . EP . . . . . . . . . . DYDQDLRVFSLYG IVDKN I IELYFND . GTVAMTNT GYRAAPLTDAELA .................KLDLRVFVDRGSVEVYVNGGH . QVLSSY TESGKLR . . . LFDVIENGQEQV . . . E . . . . . . TLDLTVVVDNAVVEVYANG.R.FALSTW

\section{H8}

VYPTE.A. IYGAA.KLFLFNNATGA.SITASLKIWE.MNSAF . . IQPFH . . . . VYPKL. A. IGKSS . HLFAFNYGYQS. VDVLNLNAWS. MNSAQ . . IS . . . . . . IYPKF.V. NNEEA. HLFVFNNGTQN. VKISEMSAWS.MKNAK. . . FVVDQSVKSAA IHPE. . N.V. . Y.NILSVK . . . . SNQVKLEVFE. LENIW . . L . . . . . . . IFPS.SD.A . . . VHARLASTGG. TTEDV.RADIYK. IASTWN . . . . . . . . FFMGEGK.Y. . PHDIQIVTDTEEPLFELESVIIRE.LNK . . . . . . . . SYAS . . EGP . . . R. A IKLVAESGS . . LKVD SLKLHH . MKS I GLELEHHHHHH . . . . ARSW . . Y.DN . . S.TQIRFFHNGEGEVQFRNVSVSEGLYNAW . . PER . . . . . . .

Figure 1. Continued. 
Table 1 Data collection and reduction statistics

\begin{tabular}{|c|c|c|c|}
\hline & $\begin{array}{l}\text { Apo } \\
\text { Pt6-SST/6-SFT }\end{array}$ & $\begin{array}{l}\text { 1-kestose } \\
\text { complex }\end{array}$ & $\begin{array}{l}\text { 6-kestose } \\
\text { complex }\end{array}$ \\
\hline Beam line & X06SA & BW7A & X06DA \\
\hline Space group & $\mathrm{P} 2{ }_{1} 2_{1} 2_{1}$ & $\mathrm{P} 2{ }_{1}{ }_{1} 2_{1}$ & $\mathrm{P} 2{ }_{1} 2_{1} 2_{1}$ \\
\hline \multirow[t]{3}{*}{ Unit-cell parameters $(\AA)$} & $a=89.1$ & $a=88.4$ & $a=88.3$ \\
\hline & $b=125.3$ & $b=123.8$ & $b=123.9$ \\
\hline & $c=148.9$ & $c=146.4$ & $c=146.7$ \\
\hline Resolution limits $(\AA)$ & $49.65-1.70(1.74-1.70)$ & $31.8-2.90(2.97-2.90)$ & $30.0-2.90(2.95-2.90)$ \\
\hline Unique observations & $182931(26$ 469) & $36335(5243)$ & $36716(1824)$ \\
\hline Redundancy & $6.7(6.7)$ & $7.2(7.0)$ & $6.7(6.7)$ \\
\hline Completeness (\%) & $99.9(100.0)$ & $99.9(100.0)$ & $100.0(100.0)$ \\
\hline Mean $/ / \sigma$ & $12.7(2.8)$ & $12.3(4.6)$ & $9.5(3.0)$ \\
\hline$R_{\text {sym }}(\%)$ & 9.5 [3.9] (88.3) & $15.6[6.3](44.6)$ & 18.6 [7.3] (56.6) \\
\hline
\end{tabular}

Values in parentheses indicate data for the highest of ten resolution shells. A value for $R_{\text {sym }}$ is also given for the lowest-resolution shell (in square brackets). X06SA and X06DA are beamlines at the Swiss Light Source synchrotron (Paul Scherrer Institut, Villingen, Switzerland); BW7A is a beamline at the Deutsches Elektronen Synchrotron (Hamburg, Germany).

space group $\mathrm{P} 2{ }_{1} 2{ }_{1} 2_{1}$, with two Pt6-SST/6-SFT molecules per asymmetric unit. These molecules ( $A$ and $B$ ) show a non-crystallographic two-fold symmetry axis. Size-exclusion chromatography data (not shown) and interface analysis between the two crystallographic monomers using the program PISA (Krissinel and Henrick, 2007) indicated that Pt6-SST/6-SFT is a monomer in solution. No significant structural differences were observed between the two chains of the dimer for either the Pt6-SST/6-SFT apo crystal or the 1-kestose or 6-kestose complexes. After superimposing the two chains, the root mean-square deviations (RMSD) of respective $C \alpha$ positions were 0.19 , 0.19 and $0.25 \AA$ in the three structures, respectively. The RMSD of the $C \alpha$ positions for the apo structure (chain $A+B$ ) versus 1-kestose (chain $A+B$ ) and 6-kestose (chain $A+B$ ) bound structures were 0.98 and $0.43 \AA$, respectively. Similar to GH32 members (Alberto et al., 2004), Pt6-SST/6-SFT shows a $\beta$-propeller domain (residues 7-342, Figure 2) and a $\beta$-sheet domain (residues 348-545, Figure 2) linked by a short $\alpha$-helix H5 (residues 343-347, Figure 2b). The $\beta$-propeller domain consists of five radially oriented blades (I-V), each consisting of four antiparallel $\beta$-strands (A-D). Blade $V$ is interrupted between $\beta$-strands $B$ and $C$ by the $\alpha$-helix H4 (residues 308-315) that interacts with the $\mathrm{N}$-terminal $\alpha$-helix $\mathrm{H} 1$ (residues 12-17), followed by a small $\beta$-sheet (residues 316-318) that has three hydrogen bonds with strand $A$ of blade I. The $\beta$-propeller domain is further stabilized by a 'molecular velcro', a term that indicates closure of the $\beta$-propeller by joining of both termini in the same $\beta$-sheet (Paoli, 2001). Blade I has two small extra $\beta$-strands (Figure $2 b$ ), one following $\alpha$-helix $\mathrm{H} 4$ and the other at the $\mathrm{C}$-terminus, forming a double closure of six $\beta$-strands in an atypical $1+4+1$ arrangement, a feature that was also observed in Ci1-FEHIla (Verhaest et al., 2005) and AtcwINV1 (Verhaest et al., 2006). The $\beta$-sheet domain
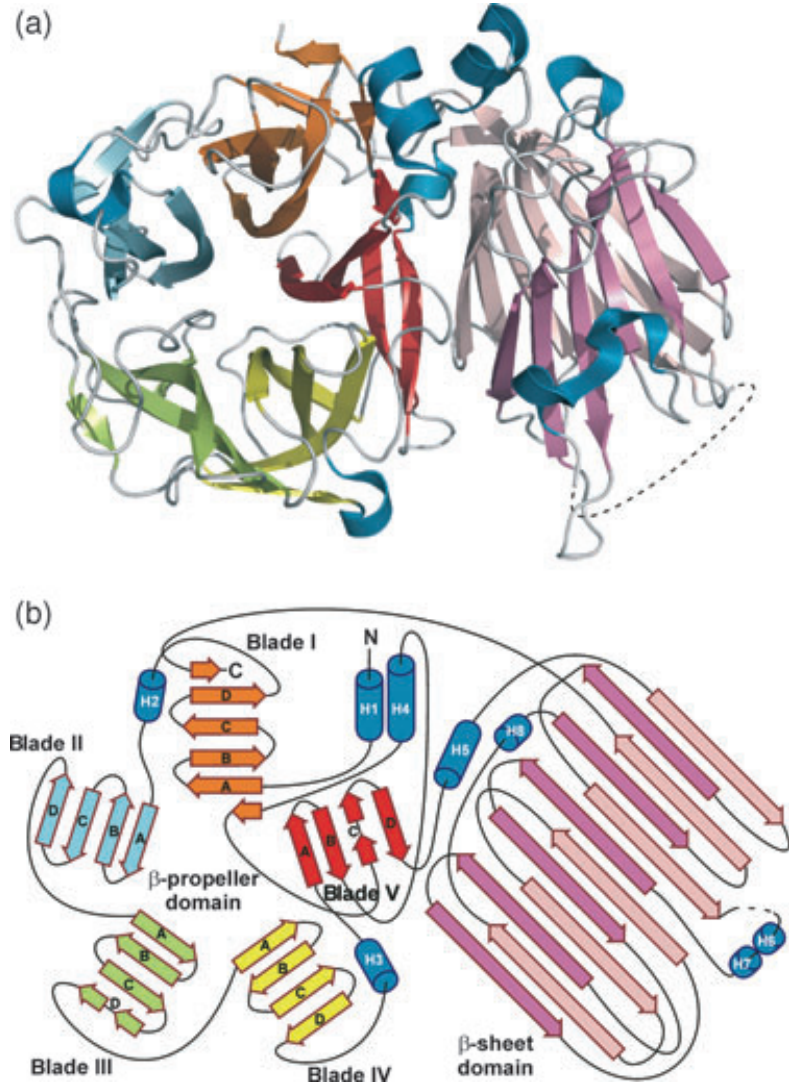

Figure 2. Overall structure of Pt6-SST/6-SFT (a) and its topology (b). $\beta$-strands are indicated by arrows, $\alpha$-helices $(\mathrm{H} 1-\mathrm{H} 8)$ are indicated by cylinders. Gaps in the structure are indicated by dashes. The structural motif was determined using PROMOTIF version 3.0 (Hutchinson and Thornton, 1996) using data generated by PDBsum (http://www.ebi.ac.uk/pdbsum) (Laskowski, 2001, 2009).

has two six-stranded antiparallel $\beta$-sheets, forming a sandwich-like fold. In the latter domain, one disulfide bond is found between cysteines 401 and 449 . 
Four naturally occurring glycosylation sites were allocated in the electron density maps on both $A$ and $B$ molecules (Table 2) at residues N59, N178, N400 and N521 (Figure S1). The glycosyl chains comprise $\mathrm{N}$-acetylglucosamine, mannose, fucose and/or xylose moieties matching typical complex glycosylation patterns in plants (Lerouge et al., 1998). These glycosyl chains are located far away from the active site, so it is unlikely that they influence enzyme activity or substrate specificity. However, they may play a role in overall enzyme stability. Furthermore, in each monomer, a single sulfate ion is bound near residue $\mathrm{Y} 136$, as well as a few glycerol molecules (Table 2).

\section{Active site}

The active site is located in the deep central pocket of the $\beta$-propeller domain (Figure 3). The catalytic triad was identified as D33 (nucleophile, part of the WMNDPNG motif; occurring as WMSDPDG in Pt6-SST/6-SFT), D157 (transitionstate stabilizer, part of the FRDA motif) and E211 (acid/base catalyst of the WECVD motif) by superposition and comparison with the active site of other $\mathrm{GH} 32$ enzymes (Figures 1 and S2). A unique feature in Pt6-SST/6-SFT is that the nucleophile D33 forms a hydrogen bond with the ring nitrogen of W302. This tryptophan has structural equivalents in all other structurally characterized GH32 members (Figure 1), but a different rotamer conformation is observed in Pt6-SST/6-SFT. The acid/base catalyst (E211) forms

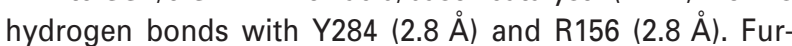
thermore, R156 forms a hydrogen bond with E117 (2.9 $⿱$ A) (Figure 3). All plant 6-SFTs show a glutamate in this position, but glutamine is observed in other plant FTs, FEHs and invertases (Figure 4). A glutamate is found in Pt6-SST/6-SFT, AjFT and Thermotoga maritima $\beta$-fructosidase (Figure 1). Typically, plant GH32 invertases have an aromatic zone at the rim of the active site (e.g. W20, W47, W82 and W302 in AtcwINV1; Figures 4 and S2). The presence of this zone is believed to be important for optimal and stable binding of Suc to AtcwINV1 (Lammens et al., 2009). This zone is not

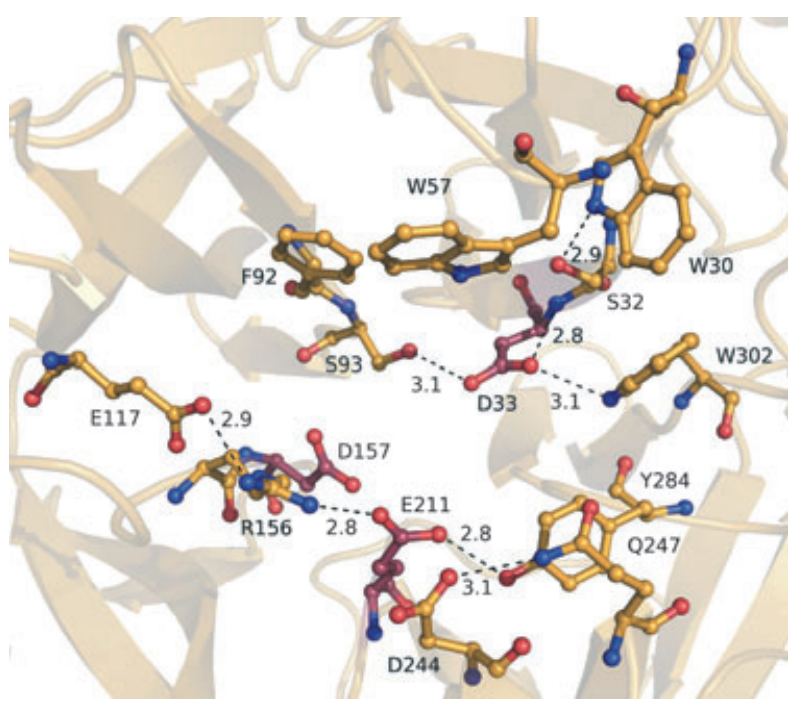

Figure 3. Close view of the active site of Pt6-SST/6-SFT, located in the $\beta$-propeller domain.

The catalytic triad (acid/base catalyst E211, transition-state stabilizer E157 and nucleophile D33) is shown in purple. Distances are shown in Ångströms.

completely conserved in plant FTs (Figure 4) and the fungal AjFT (Figures 1 and S2D). However, in Pt6-SST/6-SFT, the aromatic zone is rather conserved (Figure S2), but with a phenylalanine (F92) instead of a tryptophan in the WSGSAT motif (Figure 4). The side chain of F92 in Pt6-SST/6-SFT shows a unique orientation among all structurally identified GH32 members, being more or less perpendicular to the phenylalanines in AjFT, $S$. occidentalis invertase, T. maritima $\beta$-fructosidase and Aspergillus awamori exo-inulinase and to the corresponding tryptophan equivalents in AtcwINV1 and Ci1-FEHIla (Figure S2). It was reported previously that the specific orientation of W82 (in the WSGSAT motif) in Ci1-FEHIla (the structural equivalent of F92 in Pt6-SST/6-SFT) determines Suc inhibition (Verhaest et al., 2007; Le Roy et al., 2008; Van den Ende et al., 2009).

Table 2 Refinement statistics for the apo structure of Pt6-SST/6-SFT and its complexes with 1-kestose and 6-kestose

\begin{tabular}{|c|c|c|c|}
\hline & Apo Pt6-SST/6-SFT & 1-kestose complex & 6-kestose complex \\
\hline Reflections (working/test) & $173661 / 9166$ & 34 454/1810 & $34880 / 1836$ \\
\hline Total number of non-hydrogen atoms & 9809 & 8786 & 8752 \\
\hline Total number of protein atoms & 8367 & 8328 & 8328 \\
\hline Glycosylation sites & 8 & 8 & 8 \\
\hline Sugar molecules & 0 & $2 \times 1$-kestose & $1 \times 6$-kestose \\
\hline Water molecules & 993 & 32 & 0 \\
\hline Glycerol molecules & 13 & 2 & 2 \\
\hline$R_{\text {work }}(\%)$ & 17.09 & 19.56 & 19.69 \\
\hline$R_{\text {free }}(\%)$ & 18.65 & 23.38 & 24.04 \\
\hline RMSD bond lengths $(\AA)$ & 0.008 & 0.007 & 0.007 \\
\hline RMSD bond angles $\left({ }^{\circ}\right)$ & 1.114 & 1.136 & 1.129 \\
\hline
\end{tabular}

RMSD, root mean-square deviation. 


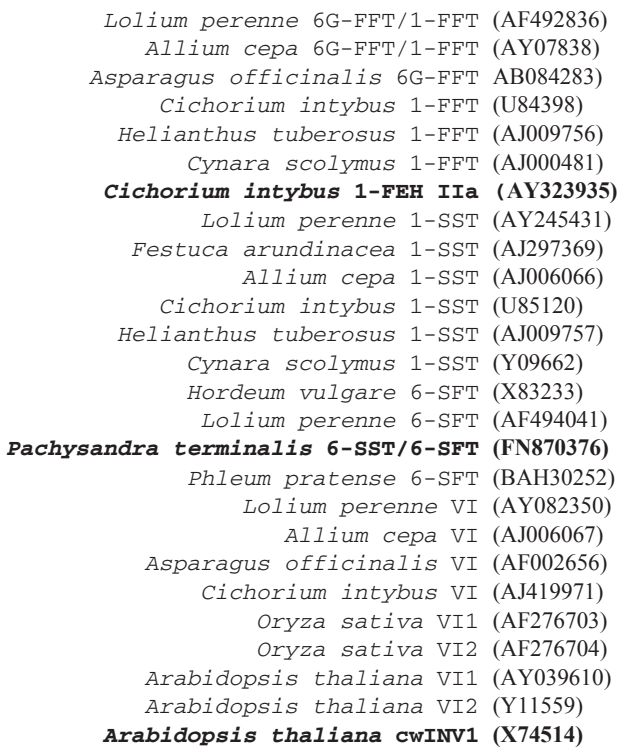

\begin{tabular}{|c|c|c|}
\hline YMNDPNG & WGN & LTGSIT \\
\hline YMNDPSG & WGN & WTGSII \\
\hline YMNDPSG & WGD & WTGSIT \\
\hline FIYDPNG & WGN & LSGSTT \\
\hline FIYDPDG & WGN & LSGSTT \\
\hline FIYDPNG & WGN & LSGSTT \\
\hline${ }^{-9}$ IMNDPNG $^{25}$ & ${ }^{46} \mathrm{FGD}^{48}$ & ${ }^{82} \mathrm{WSGSAT}^{87}$ \\
\hline YMNDPNG & WGN & LTGSIT \\
\hline YMNDPNG & WGN & LTGSIT \\
\hline FMADPNA & WDY & WSGYAT \\
\hline FISDPDG & WGN & MTGSAT \\
\hline FISDPDG & WGN & MTGSAT \\
\hline YISDPDG & WGN & MTGSAT \\
\hline YMSDPNG & WDD & LSGSMT \\
\hline FMSDPNG & WDD & LSGTIT \\
\hline WMSDPDG ${ }^{36}$ & ${ }^{57} \mathrm{WGN}^{59}$ & ${ }^{92} \mathrm{FSGSAT}^{97}$ \\
\hline FMSDPNG & WDD & LSGSIT \\
\hline WMNDPNG & WGN & WSGSAT \\
\hline WMNDPNG & WGN & WTGSAT \\
\hline WMNDPNG & WGD & WTGSAT \\
\hline WMINDPNG & WGK & WTGSAT \\
\hline WMNDPNG & WGN & WTGSAT \\
\hline WMNDPNG & WGN & WTGSAT \\
\hline WMNDPNG & WGD & WTGSAT \\
\hline WMNDPNG & WGD & WTGSAT \\
\hline 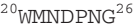 & ${ }^{47} \mathrm{WGN}^{49}$ & ${ }^{82} \mathrm{WSGSAT}^{87}$ \\
\hline
\end{tabular}

QVQ
QSI
QIM
QLQ
QLQ
QLQ
${ }^{107} \mathrm{QVQ} \mathrm{Q}^{109}$
$\mathrm{QVQ}$
$\mathrm{QVQ}$
$\mathrm{QVQ}$
$\mathrm{QLQ}$
$\mathrm{QVQ}$
$\mathrm{QLQ}$
$\mathrm{EVQ}$
$\mathrm{ESQ}$
${ }_{117} \mathrm{EML} \mathrm{I}^{119}$
$\mathrm{EVQ}$
$\mathrm{QVQ}$
$\mathrm{QVQ}$
$\mathrm{QVQ}$
$\mathrm{QVQ}$
$\mathrm{QVQ}$
$\mathrm{QVQ}$
$\mathrm{QVQ}$
$\mathrm{QVQ}$
$107 \mathrm{QVQ}$
$\mathrm{QV}$

Figure 4. Multiple alignment of amino acids of a selection of plant GH32 enzymes in the vicinity of the active pocket that are believed to play crucial roles in donor and acceptor substrate selectivity within the plant sub-family.

The three structurally characterized enzymes within the plant sub-family (Ci1-FEHIla, AtcwINV1 and Pt6-SST/6-SFT) are shown in bold. Key amino acids W30, S32, W57, F92, E117, D244, Q247, W302 and N319 are highlighted in orange in Pt6-SST/6-SFT. The nucleophile D33 is highlighted in yellow. F92 and W302 (underlined) have a unique orientation in Pt6-SST/6-SFT.

Further, in AtcwINV1, the D239/K242 couple is known to be essential to optimize binding and stabilization of Suc as a donor substrate in the active site (Le Roy et al., 2007; Lammens et al., 2008, 2009; Van den Ende et al., 2009). Therefore, the presence or absence of a D239 equivalent is one of the key determinants in predicting the functionality of an uncharacterized plant GH32 enzyme (Van den Ende et al., 2009). Intriguingly, Pt6-SST/6-SFT contains a modified D239/ K242 equivalent (D244/Q247 in Figures 4 and S2) on the loop between strands $B$ and $C$ of blade IV (Figure $2 b$ ). Similar to AtcwINV1, it is likely that this couple is involved in stabilization of Suc as a donor substrate (Figure S3) by interacting with the Glc moiety of Suc. The hydrogen bond between the OD1 atom of D244 and the NE2 atom of 0247 (3.0 ; Figure 3) appears to be indispensable to hold D244 in the correct orientation towards the active site. So far, all plant S-type GH32 enzymes have been found to possess such typical D/K or D/R couples (Figure 4) (Van den Ende et al., 2009): Pt6-SST/6-SFT is the only exception. The unique $D / Q$ couple $\left({ }^{244} \mathrm{DEOQ}^{247}\right)$ in Pt6-SST/6-SFT may be essential to establish the unique dual 6-SST/6-SFT characteristics of this enzyme (Van den Ende et al., 2011a), as further discussed below.

\section{Soaks with 1-kestose and 6-kestose}

In addition to the apo Pt6-SST/6-SFT structure, the structures of the Pt6-SST/6-SFT 1-kestose and Pt6-SST/6-SFT 6-kestose complexes were determined (Figure 5). Two 1-kestose molecules were observed in the 1-kestose soak, one each in the active sites of the two molecules in the asymmetric unit cell. However, only one 6-kestose molecule (in chain B) was observed in the 6-kestose soak. Because of the lack of highquality electron density, the 6-kestose molecule was omitted in the active site of chain $A$. Despite the relatively low resolution of the complex structures ( $2.9 \AA$ for both soaks), they reliably reveal the substrate binding mechanism.

Unexpectedly for an S-type of enzyme (using Suc as preferential donor), 1-kestose was found in a donor-like position, binding at the $-1,+1$ and +2 donor subsites (nomenclature according to Davies et al., 1997) (Figures 5a and S4), similar to the 1-kestose soaks of Ci1-FEHIla (Protein Data Bank ID 2AEZ) (Verhaest et al., 2007) and AjFT (Protein Data Bank ID 3LDR) (Chuankhayan et al., 2010). The terminal Fru of the 1-kestose molecule binds almost identically at the -1 donor subsite as observed for all other plant GH32 structures, stabilized by the transition-state stabilizer D157 (2.9 ̊). This Fru moiety also forms a hydrogen bond (3.1 $\AA$ ) with the nitrogen of W57 (Figure 5a), as observed previously in AtcwINV1 (W47; Lammens et al., 2009). The 03 hydroxyl of the Fru at the +1 donor subsite forms a hydrogen bond with OD1 of D244 (2.7 $\AA$ ) of the D244/0247 couple (Figure 5a). Furthermore, the terminal Glc subunit at the +2 subsite stacks with W57 (Figure 5a). Remarkably, compared to the active site of apo Pt6-SST/6-SFT, the active site of the 1-kestose soak shows a completely different orientation of F92 (compare Figures 5a and 3). This feature was also observed in the 6-kestose soak (Figure 5b), in which F92 takes the same orientation as observed in the 1-kestose soak. It appears that the aromatic ring of F92 rotates approximately $90^{\circ}$ upon kestose binding, indicating its stabilizing role during substrate binding. 

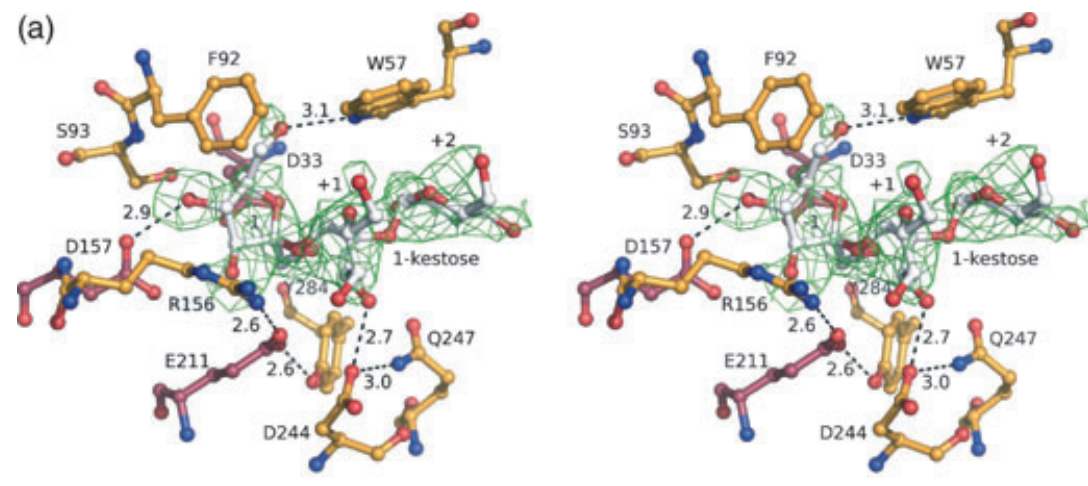

Figure 5. Stereo images of the active site of the Pt6-SST/6-SFT complexes.

(a) Pt6-SST/6-SFT in complex with 1-kestose. The 1-kestose molecule (white) binds at the $-1,+1,+2$ donor binding sites.

(b) Pt6-SST/6-SFT complex with 6-kestose. The 6kestose molecule (white) binds at the $+1,+2,+3$ acceptor binding sites.

The catalytic triad is shown in purple. The $F_{o}-\mathrm{F}_{c}$ electron density map for the ligand is shown at the $2.5 \sigma$ contour level. The map was calculated after the removal of the ligand from the final model. Distances are shown in Ångströms.

(b)
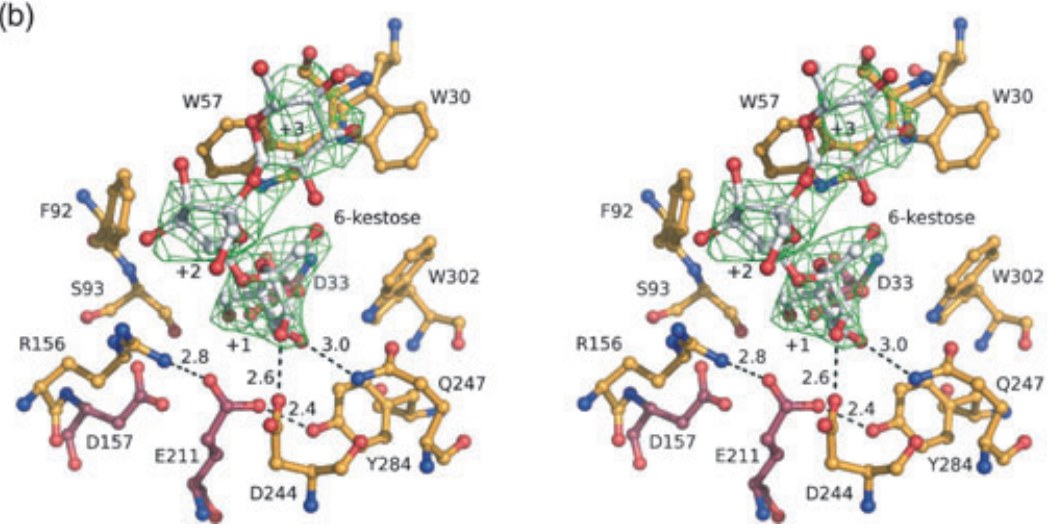

In contrast to the structure with 1-kestose, which probably does not represent a productive binding mode (see Discussion), it is likely that the 6-kestose in the Pt6-SST/6SFT 6-kestose soak represents a genuine acceptor binding mode at the $+1,+2$ and +3 acceptor binding subsites (Figure $5 \mathrm{~b}$ ). Clearly, the terminal Fru unit of 6-kestose does not bind at the same place as for previously solved plant GH32 substrate/inhibitor complexes (Figures $5 b$ and S4) (Lammens et al., 2009). Instead, the terminal Fru unit of 6-kestose binds between the acid/base catalyst E211 and the nucleophile D33 (Figures $5 b$ and 6 ). Moreover, the 06 of the terminal Fru moiety of 6-kestose is presented towards the -1 subsite (Figures $5 b$ and 6 ), and is thus available to create a $\beta(2-6)$ linkage. At the putative +1 acceptor binding site, 6 kestose is stabilized by the D244/0247 couple (Figure 5b). The hydrogen bond between D244 and Q247 (as observed in the apo structure, Figure 3) is broken, and instead both residues stabilize the terminal Fru molecule of the 6-kestose acceptor by binding $\mathrm{O} 3(2.6 \AA)$ and $\mathrm{O} 4(3.0 \AA)$, respectively (Figure 3). The stabilization of the Fru moiety at the +2 subsite and the Glc moiety at the +3 binding site cannot be explained by formation of hydrogen bonds. However, similar to the role for W82 in the Ci1-FEHIla/Suc complex (Verhaest et al., 2007) and the hydrophobic rim of tryptophans in the AtcwINV1/Suc complexes (Lammens et al., 2008), it appears that W57 and F92 (Figures $5 \mathrm{~b}$ and 6 ) play an important role in binding of the acceptor molecule.

\section{$\mathrm{p} K_{\mathrm{a}}$ modulation of the acid/base catalyst by ligand binding at the donor site}

A recent calculation of the $\mathrm{p} K_{\mathrm{a}}$ values for the acid/base catalysts within all structurally characterized Clan-J members (S.Y.; K.L.R.; T. Venken, KU Leuven, Biochemistry, Molecular and Structural Biology; W.L.; W.V.d.E; Marc De Maeyer, KU Leuven, Biochemistry, Molecular and Structural Biology, unpublished results) revealed that the protonation state of the acid/base is insufficient to drive catalysis in most cases. However, donor substrate entrance in the active site pocket can increase the protonation state, but inhibitor entrance cannot (S.Y.; K.L.R.; T. Venken, KU Leuven, Biochemistry, Molecular and Structural Biology; W.L.; W.V.d.E; Marc De Maeyer, KU Leuven, Biochemistry, Molecular and Structural Biology, unpublished results). The $\mathrm{p} K_{\mathrm{a}}$ values for the acid/base catalyst E211 were calculated for the apo Pt6SST/6-SFT enzyme, the Pt6-SST/6-SFT complex with 1-kestose and the apo enzyme with docked Suc (Figure S3). The protonation state $\left(\left[\mathrm{A}^{-}\right] /[\mathrm{HA}]\right)$ of the acid/base E211 is also indicated in Table 3, calculated at $\mathrm{pH} 5.0$, the $\mathrm{pH}$ optimum of Pt6-SST/6-SFT. E211 is only partially protonated in the apo-enzyme, but Suc binding results in more complete protonation. Interestingly, E211 is hardly protonated in the 1-kestose complex (Table 3). For comparison, values are also shown for apo Ci1-FEHIla and its complex with Suc as an inhibitor and 1-kestose as a substrate (Table 3). 
Table 3 Estimated $p K_{\mathrm{a}}$ values of the acid/base catalysts in Pt6-SST/6SFT and Ci1-FEHIla apo enzymes and their complexes with Suc and 1-kestose

\begin{tabular}{|c|c|c|c|c|}
\hline Description & Residue & $\mathrm{p} K_{\mathrm{a}}$ & {$\left[\mathrm{A}^{-}\right] /[\mathrm{HA}]$} & Ligand \\
\hline \multicolumn{5}{|c|}{ 6-SST/6-SFT from Pachysandra terminalis ( $\mathrm{pH} 5$ ) } \\
\hline 3UGF & E211 & 3.6 & 25.1 & - \\
\hline 3UGG & E211 & 1.6 & 2511.9 & 1-kestose \\
\hline Docking & E211 & 8.8 & 0.0002 & Suc \\
\hline \multicolumn{5}{|c|}{ 1-FEHIla from Cichorium intybus (pH 5) } \\
\hline 1ST8 & E201 & 3.0 & 100 & - \\
\hline Docking & E201 & 5.4 & 0.3 & 1-kestose \\
\hline 2ADD & E201 & 3.3 & 50.1 & Suc \\
\hline
\end{tabular}

\section{DISCUSSION}

Plant FTs evolved from vacuolar invertase ancestors, an event that probably occurred several times during evolution (Wei and Chatterton, 2001; Ritsema et al., 2006; Altenbach et al., 2009), leading to the observed diversity in FTs and fructan types in the plant kingdom. The unexpected discovery of both levan- and graminan-type fructans in Pachysandra terminalis, a representative of the basal eudicots, further confirmed the polyphyletic origin of fructan biosynthesis (Ritsema et al., 2006; Van den Ende et al., 2011a). Instead of accumulating inulin-type fructans as observed in a number of core eudicot families, the presence of grass-type fructans in $P$. terminalis suggests a unique evolution from a vacuolar invertase to an $\mathrm{FT}$ in this branch. It was found that $P$. terminalis rhizomes accumulate an FT (Pt6-SST/6-SFT) at high concentrations. Its multi-functional character, combining different FT activities (6-SST, 6-SFT and some 1-SST activity) with intrinsic hydrolase activities (Van den Ende et al., 2011a), indicated that Pt6-SST/6-SFT did not yet reach the endpoint of the evolutionary process, i.e. a highly specific FT with single functionality. Nevertheless, the unique Pt6-SST/6SFT was able to produce the same graminan- and levan-type fructans in vitro as observed in vivo in $P$. terminalis. On the one hand, the enzyme can $\beta(2-6)$ elongate on terminal Fru in Suc, 6-kestose and higher-DP levans. On the other hand, it can introduce branches on 1-kestose to produce bifurcose, and higher-DP graminans by further adding $\beta(2-6)$ linkages. 1-kestose was found to be a poor donor substrate for this enzyme (Van den Ende et al., 2011a), indicating that evolution had progressed far enough to use Suc as the preferential donor substrate. However, the enzyme still allows a range of possible acceptor substrates (Suc, 1-kestose, 6-kestose and water). Therefore, the specific characteristics of this Pt6-SST/ 6-SFT make it an excellent template to study FT evolution in greater detail by site-directed mutagenesis and modeling approaches. Furthermore, graminan-type fructans are emerging as powerful prebiotics and antioxidants, and variants of this enzyme could lead to the production of superior fructans for plant protection and/or food applications.
Although considerable progress has been made in unraveling structure-function relationships for plant GH32 members, rapid progress has been hampered by the absence of a 3D structure of a plant FT. Therefore, the release of the Pt6SST/6-SFT structure and its complex with 6-kestose will boost this research area. So far, all the enzymes within the $\mathrm{GH} 32$ family for which structures have been obtained were of recombinant origin and produced by heterologous expression. In contrast, Pt6-SST/6-SFT was purified from a native source, leaving no doubts as to its correct folding or glycosylation.

The Pt6-SST/6-SFT described here synthesizes completely different types of fructans to the inulin-type fructans produced by AjFT (Chuankhayan et al., 2010). Although many substrate/inhibitor complexes have been generated previously within the GH32 and GH68 families (Lammens et al., 2008, 2009; and references therein; Chuankhayan et al. 2010; Pijning et al., 2011), all these ligands were bound at the $-1,+1, \ldots,+n$ subsites, representing the donor substrate position. By contrast, the Pt6-SST/6-SFT 6-kestose complex shows real acceptor substrate binding at the acceptor subsites $+1,+2,+3$. Such acceptor binding sites with bound substrate are rarely reported within glycoside hydrolases (Johansson et al., 2004, and references therein).

The binding of 1-kestose at the donor site in the 1-kestose soak came as a surprise, as 1-kestose is known to be a poor donor substrate for this enzyme. The probable physiological irrelevance of this complex was further confirmed by $\mathrm{p} K_{\mathrm{a}}$ determinations on the acid/base nucleophile in the 1-kestose complex (Table 3). The poor protonation status of E211 suggests that catalysis is inhibited when 1-kestose binds. Conversely, upon binding of Suc, the unfavorable protonation state of the Pt6-SST/6-SFT apo enzyme was shifted to a favorable one (Table 3), allowing fast catalysis. Taken together, these observations show that soaking crystals in very high carbohydrate concentrations risks production of physiologically irrelevant donor site complexes. The irrelevance of such complexes can only be detected by placing the structural data into a proper physiological context. In this respect, the relevance of the recently obtained inulosucrase structure in complex with 1-kestose at the donor position (Pijning et al., 2011) perhaps requires reconsideration, as Suc (not 1-kestose) is the preferential donor substrate of this enzyme.

Intriguingly, previously identified amino-acid substitutions involved in the development of transfructosylation capability in invertases (e.g. W to $\mathrm{Y}$ or $\mathrm{F}$ and/or $\mathrm{N}$ to $\mathrm{S}$ in the WMNDPNG motif, and WGW to WGY or WGF) (Schroeven et al., 2008; Altenbach et al., 2009) were only partially present in Pt6-SST/6-SFT (Figure 4). Although an Asn to Ser (S32) substitution occurred in the WMNDPNG motif (Figure 4), the tryptophan (W30) was maintained in this motif (Figure 4) and a unique hydrogen bond was observed between S32 and the ring nitrogen of W30 (3.0 ^) (Figure 3). 
Invertases contain a unique hydrogen bond network between Trp and Asn, and its destruction by a WMN to YMS substitution leads to creation of a 1-SST (Schroeven et al., 2008). Furthermore, the nucleophile D33 forms a hydrogen bond with W302 (3.1 $\AA$ ), which has a distinct orientation compared with all other $\mathrm{GH} 32$ structures. It can be hypothesized that the unique combined W30-S32 interaction and W302 orientation allow transfructosylation capability with some remaining hydrolytic activity. Why does W302 occupy a different orientation in Pt6-SST/6-SFT? A closer inspection of the structures reveals that the nitrogens in the central ring of W292 (Ci1-FEHIla) and W297 (AtcwINV1) form a hydrogen bond with the backbone carbonyl oxygen of the methionine of the WMNDPNG motif. In Pt6-SST/6SFT, this function has been taken over by an asparagine (N319, GWAX motif in Figure 4), while AtcwINV1 and Ci1-FEHIla contain a glycine (G309 and G314) at this position. As the nitrogen in the central ring of Pt6-SST/6-SFT W302 can no longer bind with the backbone carbonyl oxygen, it is able to adopt its atypical rotamer configuration. Therefore, this critical amino acid in the GWAX motif, which shows considerable variation among plant FTs (Figure 4), may be indirectly involved in acceptor substrate specificity determination, through its effect on the rotamer configuration of its neighboring tryptophan.

Diverse residues have already been shown to play particular roles in donor and acceptor specificity in $\mathrm{GH} 32$ enzymes (Altenbach et al., 2009; and references therein; Van den Ende et al., 2009). Some hydrophobic residues in the WGN and WSGSAT motifs (Figure 4) are conserved and appear to be important for stabilizing any incoming donor/acceptor substrate (or inhibitor). For instance, it was shown that the presence of a bulky hydrophobic residue in the WGN motif stabilizes the binding of donor Suc in AtcwINV1. A W47L mutant showed a very large increase in the $K_{m}$ value for Suc in comparison to the wild-type enzyme (Le Roy et al., 2007). In the Pt6-SST/6-SFT 1-kestose complex (Figure 5a), the corresponding W57 stacks with the Glc subunit, and also stabilizes 6-kestose as an acceptor substrate (Figure 5b). Hence, it appears that the hydrophobic residue of the WGN motif may play a role in both donor and acceptor stabilization in Pt6-SST/6-SFT. In contrast to Pt6-SST/6-SFT (Figure S5A), AjFT lacks a WGN motif (Figures 1 and S5A). It also contains smaller residues in the vicinity of the nucleophile (G59, L78, G81 in Figure S5), perhaps allowing entrance of acceptor substrates in this area, but this requires further investigation. Both AjFT and Pt6-SST/6-SFT contain a Phe equivalent (F118, F92) in the WSGSAT motif but with a different orientation (Figure S5). Most plant FEHs (but not Ci1-FEHIla) also contain a Phe in this motif. Site-directed mutagenesis of the homolog residues in Ci1-FEHIla, AtcwINV1 and Beta vulgaris 6-FEH showed that overall binding of the substrate is highly affected (Le Roy et al., 2008). The equivalent $\mathrm{F} 118$ residue in $\mathrm{AjFT}$ is also involved in substrate stabilization (Chuankhayan et al., 2010). Intriguingly, the orientation of the equivalent residue in Pt6-SST/6-SFT (F92) is completely different in the apo and the two kestose-bound structures, suggesting that the F92 orientation is adapted to the incoming ligands.

Previously, it was demonstrated that the D239/K242 couple (AtcwINV1 terminology) plays a vital role in Suc stabilization in AtcwINV1 (Le Roy et al., 2007; Lammens et al., 2008). In Pt6-SST/6-SFT, the equivalent couple is D244/ Q247. In the complex with 1-kestose, D244 forms a hydrogen bond with the Fru at the +1 donor subsite. More importantly, both D244 and Q247 also stabilize the terminal Fru moiety of 6-kestose at the +1 acceptor subsite in the Pt6-SST/6-SFT 6-kestose complex, revealing its crucial role in stabilizing the terminal subunit of the incoming acceptor substrate. Thus, the $\mathrm{D} / \mathrm{Q}$ couple is probably involved in both donor and acceptor substrate binding. This fits perfectly with a previous suggestion that the equivalent N340/W343 couple in Lolium perenne $\mathrm{Lp}^{\mathrm{G}}{ }^{\mathrm{G}} \mathrm{FFT} / 1-\mathrm{FFT}$ plays a similar crucial role at the +1 subsite (Lasseur et al., 2009). Similarly, in the GH68 family, the homologues R360 (Bacillus subtilis levansucrase) and H296 (Zymomonas mobilis levansucrase) are also known to greatly determine the transfructosylation properties of these enzymes (Chambert and Petit-Glatron, 1991; Yanase et al., 2002; Li et al., 2008). Moreover, this hotspot also appears to play a key role in regulatory processes such as the formation of microfibrils associated with levan polymerization (Goldman et al., 2008) and in the interaction with proteinaceous inhibitors (Hothorn et al., 2010).

By combining structural (this study) and enzymatic data (Van den Ende et al., 2011a), a model is proposed for the Pt6SST/6-SFT donor and acceptor sites, pinpointing the key amino acids involved (Figures 6 and 7). In the first step, Suc is bound to the active site (binding at the -1 and +1 donor subsites) (Figure 6a). The terminal Fru unit is stabilized by the transition-state stabilizer D157 and the aromatic nitrogen of W57. Upon Suc binding, the D244/Q247 couple is broken, and D244 can perform its role in stabilizing the Glc subunit at the +1 donor binding site. A nucleophilic attack is performed by D33 on the anomeric carbon C2 of Suc, forming the covalent Fru-enzyme intermediate (Figure 6b). The acid/ base catalyst E211 acts as a general acid, donating a proton to the glycosyl leaving group. Glc leaves the active site, and 6 -kestose is then able to bind at the acceptor site $1+1,+2$ and +3 acceptor subsites) (Figure $6 \mathrm{c}$ ). In this position, the 6 kestose molecule is stabilized by hydrogen bonds with D244 and Q247, and by F92 and W57. The 06 of the terminal Fru is located at 3.2 and $3.4 \AA$, respectively, from the acid/base and nucleophile. In the second step, the acid/base catalyst E211 performs its role as a general base, removing a proton from 06. The Fru intermediate is hydrolyzed, creating a $\beta(2-6)$ linkage, whereupon 6,6-nystose (6,6-kestotetraose) leaves the active site (Figure $6 \mathrm{~d}$ and 7). Central to this model is the crucial dual role of the D244/0247 couple in binding both the 
(a)

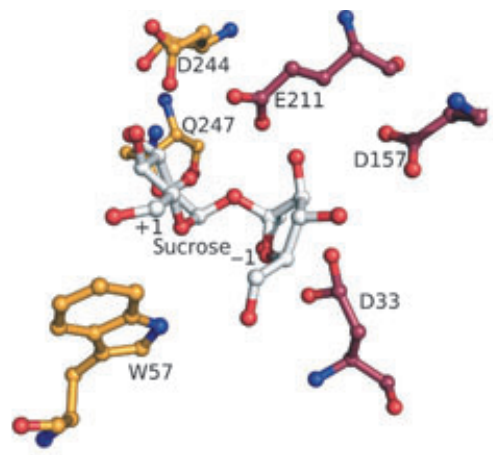

(c)

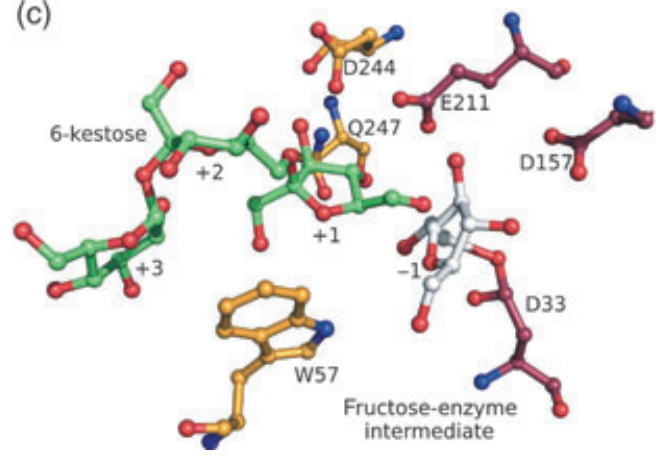

(b)

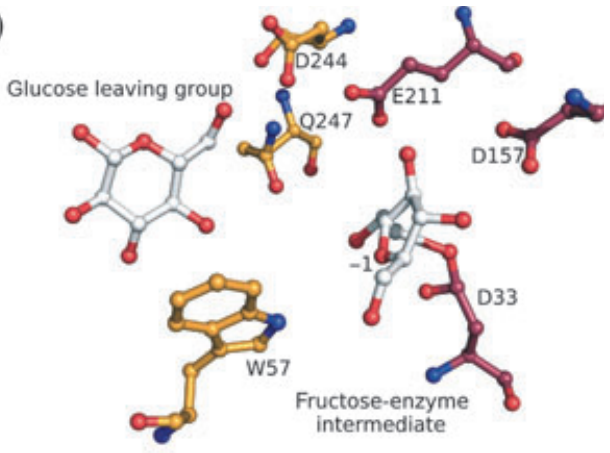

(d)

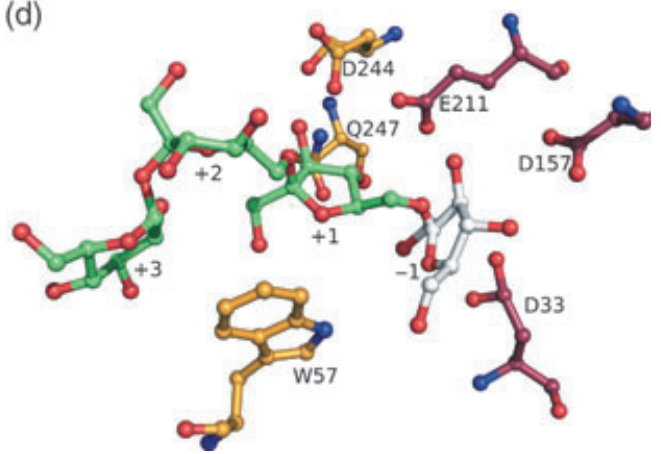

Figure 6. Proposed binding modes of donor and acceptor substrates in Pt6-SST/6-SFT. (a) Suc (white) is bound at the active site.

(b) Formation of the fructose-enzyme intermediate, with Glc leaving the active site. (c) 6-kestose (green) binds at the acceptor binding site.

(d) A $\beta(2-6)$ linkage is created, and the DP4 fructan 6,6-nystose (6,6-kestotetraose) leaves the active site.

donor and acceptor substrate. As explained above, Pt6-SST/ 6-SFT also shows some 1-SST side activity. The binding of 1kestose at the donor site (Figure 5a), although physiologically irrelevant, suggests putative binding of Suc as an acceptor at the +1 and +2 sites for formation of a $\beta(2-1)$ linkage to form 1-kestose. These observations shed light on the long-standing and intriguing issue of $\beta(2-1)$ versus $\beta(2-$ 6) Fru-Fru linkage formation within this class of enzymes. In the longer term, these findings aim at rational enzyme design within family $\mathrm{GH} 32$, and perhaps the whole Clan-J, in order to produce superior, tailor-made fructans.

In summary, a 3D structure of a genuine plant FT from a native source was obtained. No enzyme-acceptor substrate complexes could be generated so far within Clan-J, and here we present the Pt6-SST/6-SFT in complex with 6-kestose as acceptor. The multi-functional and imperfect FT characteristics of the native enzyme were linked to structural data indicating the inclusion of unique amino acids and a unique orientation of hydrophobic residues that were previously unknown in the absence of structural information. To further unravel the complexity of the substrate specificity among GH32 plant members, more intense studies on hydrophobic side-chain orientations will be necessary, in addition to extensive mutagenesis. In Pt6-SST/6-SFT, the presence of the unique $\mathrm{Gln}$ in the $\mathrm{D} / \mathrm{Q}$ couple (the equivalent of the $\mathrm{D} / \mathrm{K}$ couple) may be linked to the wide range of acceptor specificities and branching capacities of the enzyme. Extensive mutagenesis studies are underway to investigate this in greater detail.

\section{EXPERIMENTAL PROCEDURES}

\section{Purification}

The leaves and stems of Pachysandra terminalis Sieb. \& Zucc. were removed. Rhizomes were washed with cold tap water and homogenized using a Waring blender (Waring, http://www.waring products.com/) in $50 \mathrm{~mm}$ sodium acetate buffer, $\mathrm{pH}$ 5.0, containing $1 \mathrm{~mm}$ phenylmethylsulfonylfluoride, $1 \mathrm{~mm}$ mercaptoethanol, $10 \mathrm{~mm} \mathrm{NaHSO}$ and $0.1 \% \mathrm{w} / \mathrm{v}$ Polyclar AT (Serva Electrophoresis $\mathrm{GmbH}$, http://www.serva.de). For each $\mathrm{kg}$ of rhizomes, $1.0 \mathrm{~L}$ of extraction buffer were used. The homogenate was squeezed through cheesecloth. Ammonium sulfate was added to a saturation of $30 \%$, and the mixture was stirred on ice for $30 \mathrm{~min}$. After centrifugation for $20 \mathrm{~min}$ at $40000 \mathrm{~g}$, the pellet was discarded. Ammonium sulfate was added to the supernatant to a final concentration of $80 \%$, and the mixture was stirred on ice for $30 \mathrm{~min}$. After centrifugation for $20 \mathrm{~min}$ at $40000 \mathrm{~g}$, the supernatant was discarded. The precipitate was collected and redissolved in $50 \mathrm{~mm}$ sodium acetate buffer ( $\mathrm{pH}$ 5.0) supplemented with $1 \mathrm{~mm} \mathrm{CaCl}, 1 \mathrm{mM} \mathrm{MnCl}_{2}$ and $1 \mathrm{~mm} \mathrm{MgCl} 2$. Undissolved material was removed by centrifugation for $10 \mathrm{~min}$ at $40000 \mathrm{~g}$. The supernatant was applied to a Concavanalin A-Sepharose column (GE Healthcare, http://www. gehealthcare.com) equilibrated with $50 \mathrm{~mm}$ sodium acetate buffer (pH 5.0) supplemented with $1 \mathrm{~mm} \mathrm{CaCl}_{2}, 1 \mathrm{~mm} \mathrm{MnCl}_{2}$ and $1 \mathrm{~mm}$ 

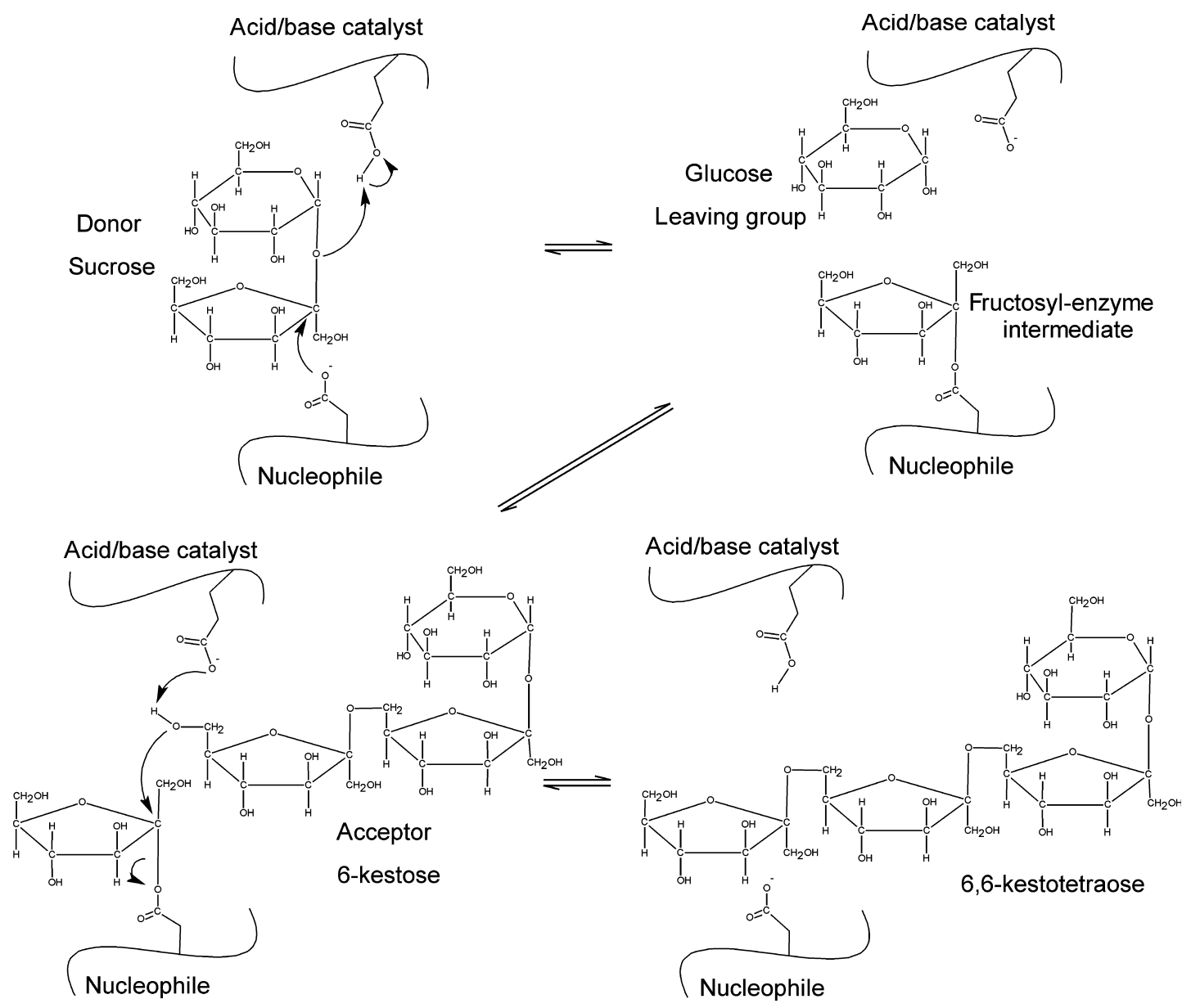

Figure 7. Proposed catalytic mechanism of Pt6-SST/6-SFT with Suc as the donor and 6-kestose as the acceptor, with formation of 6,6-kestotetraose.

$\mathrm{MgCl}_{2}$. The column was washed using the same buffer. Bound proteins were eluted using $0.5 \mathrm{~m}$ methyl $\alpha$-D-mannopyranoside in $50 \mathrm{~mm}$ sodium acetate buffer with $1 \mathrm{mM} \mathrm{CaCl}, 1 \mathrm{mM} \mathrm{MnCl}_{2}$ and $1 \mathrm{mM} \mathrm{MgCl}$. The eluate was collected, and the $\mathrm{pH}$ was adjusted to 5.3. Then proteins were loaded onto a Mono $S^{\mathrm{TM}} \mathrm{HR} 5 / 50 \mathrm{GL}$ cationexchange column (GE Healthcare) equilibrated with $50 \mathrm{~mm}$ sodium acetate buffer, pH 5.5. The flow-through was collected, and its $\mathrm{pH}$ was adjusted to 4.5. Proteins bound to the Mono $\mathrm{S}$ column were eluted using $50 \mathrm{~mm}$ sodium acetate buffer, $\mathrm{pH} 5.5$, and $1.0 \mathrm{M} \mathrm{NaCl}$. Then the flow-through from the previous step was loaded onto the Mono S column equilibrated with $50 \mathrm{~mm}$ sodium acetate buffer, $\mathrm{pH}$ 4.5. This time the flow-through was discarded, and bound proteins were eluted using a linear gradient from $0.0-0.3 \mathrm{M} \mathrm{NaCl}$ over $30 \mathrm{~min}$. Fractions of $1 \mathrm{ml}$ were collected. Active fractions (monitored by $6-\mathrm{SST} / 6-\mathrm{SFT}$ activity) were subsequently loaded onto a HiLoad $^{\text {TM }} 16 / 60$ Superdex $^{\text {TM }} 75$ prep grade column (GE Healthcare) equilibrated with $20 \mathrm{~mm}$ sodium acetate buffer, $\mathrm{pH} 5.0$, and $50 \mathrm{~mm}$ $\mathrm{NaCl}$. The most active fractions were used for crystallization after checking their purity by SDS-PAGE.

\section{Crystallization}

The active fractions were combined and concentrated using a VivaSpin ultrafiltration device (10 kDa cut-off membranes) (Sartorius Stedim Biotech, http://www.sartorius-stedim.com) to a final protein concentration of approximately $8.0 \mathrm{mg} \mathrm{ml}^{-1}$. Crystallization was performed by the hanging-drop vapor-diffusion method. Initial crystallization conditions were found using the commercially available Crystal Screens 1 and 2 (Hampton Research, http:// www.hamptonresearch.com) with drops containing equal volumes $(1 \mu \mathrm{l})$ of protein and precipitant solution, which were equilibrated against $700 \mu \mathrm{l}$ precipitant solution. The best crystals were obtained after 4 days in $0.1 \mathrm{~m}$ citrate, $\mathrm{pH} 5.6,0.7 \mathrm{~m}$ ammonium sulfate and $1.0 \mathrm{~m}$ lithium sulfate. In a single drop, numerous rod-like shaped crystals $(250 \times 25 \times 25 \mu \mathrm{m})$ appeared, together with one bigger crystal $(200 \times 200 \times 50 \mu \mathrm{m})$. Unfortunately, such large crystals could not be reproduced afterwards.

\section{Data collection, structure solution and refinement}

The large Pt6-SST/6-SFT crystal was transmitted for 5 min into cryoprotectant solution containing the precipitant solution supplemented with $25 \% \mathrm{v} / \mathrm{v}$ glycerol. In addition, two soaking experiments were performed with the smaller crystals. For the 1-kestose soak $25 \% \mathrm{w} / \mathrm{v} 1$-kestose was added to the precipitant solution, and crystals were soaked for $5 \mathrm{~min}$. For the 6-kestose soak, crystals were transferred to precipitant solution saturated with 6-kestose for $20 \mathrm{~h}$. Afterwards, all crystals were flash-cooled and stored in liquid nitrogen prior to data collection. Data for the bigger crystal (apo structure) were collected at the Swiss Light Source synchrotron (Paul Scherrer Institut, Villigen, Switzerland) using beamline X06SA. Data images were processed using XDS (Kabsch, 1993), and 
scaled and merged using SCALA (Evans, 2006) from the CCP4 suite (Collaborative Computational Project Number 4, 1994). Data for the 1-kestose soak were collected using beamline BW7A (Deutsches Elektronen Synchrotron, Hamburg, Germany) at $100 \mathrm{~K}$ (using an Oxford Cryosystems cryostream, http://www.oxcryo.com). The diffraction images were visualized and processed using iMOSFLM (Leslie, 2006), and scaled and merged using SCALA (Evans, 2006) from the CCP4 suite (Collaborative Computational Project Number 4 , 1994). Data for the 6-kestose soak were collected using beamline X06DA of the Swiss Light Source synchrotron. The diffraction images were visualized using XdisplayF, processed using DENZO, and scaled and merged using SCALEPACK version 1.97.2. from the HKL suite of programs (Otwinowski and Minor, 1997). Crystals belong to the same orthorhombic space group P $2{ }_{1} 2_{1} 2_{1}$. Complete data collection and reduction statistics are given in Table 1.

\section{Structure solution, refinement and validation}

Pt6-SST/6-SFT shows $41 \%$ sequence identity (58\% sequence similarity) with AtcwINV1 (calculated using ClustalW, http://www.ebi. ac.uk/Tools/msa/clustalw2). The crystallographic phase problem was solved by molecular replacement using the MOLREP program (Vagin and Teplyakov, 1997) of the CCP4 package, with AtcwINV1 (Protein Data Bank ID 2AC1) as a model (Verhaest et al., 2006). Several cycles of refinement and manual model building were performed using Refmac5 (Murshudov et al., 1997) and Coot (Emsley and Cowtan, 2004), respectively. For all datasets, the same $5 \%$ of observations were set aside for cross-validation analysis. 'Medium' NCS restraints linking the two molecules in the asymmetric unit were used, and TLS refinement was performed using two groups representing the two molecules. NCS was not used at the final stage of refinement. The final Pt6-SST/6-SFT structures were validated using MolProbITY (Davis et al., 2004) and SFCHECK (Vaguine et al., 1999). Root mean-square deviations (RMSDs) were calculated using LSOKAB (Collaborative Computational Project Number 4, 1994). The Pt6-SST/6-SFT structures show some areas with an uninterpretable electron density map, located in disordered loops far from the active site (indicated by dashes in Figure 2a,b). Complete refinement statistics are shown in Table 2.

\section{Docking}

Structures were imported into Maestro9.2 (Banks et al., 2005) in order to run a restrained minimization that removed unfavorable steric contacts and improved the quality of the protein hydrogen bonding network without large rearrangements of the protein heavy atoms. Docking of Suc as donor substrate in Pt6-SST/6-SFT and 1kestose in Ci1-FEHlla was performed using Glide (Friesner et al., 2004, 2006) in Schrödinger 2011(http://www.schrodinger.com/ downloadcenter/). The docking binding regions were defined by cubic boxes centred on the ligand mass center, with sizes of $10 \AA$ (Suc) and $12 \AA$ (1-kestose), respectively. Subsequently, extra-precision docking and scoring was performed. Twenty poses were included in post-docking minimization for bond length and angle as well as torsional angle optimization. Poses were re-scored using a scaled Coulomb-van der Waals term and the GlideScore system (Friesner et al., 2006). The best scored pose was chosen as the optimal solution.

\section{ACCESSION NUMBERS}

Atomic coordinates and structure factor files have been deposited in the Protein Data Bank: ID 3UGF for apo Pt6-SST/6-SFT, ID 3UGG for Pt6-SST/6-SFT in complex with 1-kestose, and ID 3UGH for Pt6-SST/ 6-SFT in complex with 6-kestose.

\section{ACKNOWLEDGEMENTS}

The authors thank the beamline scientists of the Deutsches Elektronen Synchrotron for technical support, the European Union for their support through the Research Infrastructure Action under the "FP6 Structuring the European Research Area Programme", contract No RII3/CT/2004/5060008. 6-kestose was kindly provided by $\operatorname{Dr}$ Masaru lizuka (Kobe Shoin Women's University, Kobe, Japan). W.L., K.L.R. and W.V.d.E. are supported by grants from the Fonds Wetenschappelijk Onderzoek Vlaanderen and the Research Fund of the Katholieke Universiteit Leuven.

\section{SUPPORTING INFORMATION}

Additional Supporting Information may be found in the online version of this article:

Figure S1. Pt6-SST/6-SFT glycosylation.

Figure S2. Active site comparison of selected GH32 structures.

Figure S3. Docking of Suc in Pt6-SST/6-SFT.

Figure S4. Surface images of selected GH32 complexes.

Figure S5. Stereo image of the active sites of Pt6-SST/6-SFT and AjFT.

Please note: As a service to our authors and readers, this journal provides supporting information supplied by the authors. Such materials are peer-reviewed and may be re-organized for online delivery, but are not copy-edited or typeset. Technical support issues arising from supporting information (other than missing files) should be addressed to the authors.

\section{REFERENCES}

Alberto, F., Bignon, C., Sulzenbacher, G., Henrissat, B. and Czjzek, M. (2004) The three-dimensional structure of invertase ( $\beta$-fructosidase) from Thermotoga maritima reveals a bimodular arrangement and an evolutionary relationship between retaining and inverting glycosidases. J. Biol. Chem. 279, 18903-18910.

Altenbach, D., Nuesch, E., Meyer, A.D., Boller, T. and Wiemken, A. (2004) The large subunit determines catalytic specificity of barley sucrose:fructan 6-fructosyltransferase and fescue sucrose:sucrose 1-fructosyltransferase. FEBS Lett. 567, 214-218.

Altenbach, D., Rudino-Pinera, E., Olvera, C., Boller, T., Wiemken, A. and Ritsema, T. (2009) An acceptor-substrate binding site determining glycosyl transfer emerges from mutant analysis of a plant vacuolar invertase and a fructosyltransferase. Plant Mol. Biol. 69, 47-56.

Alvaro-Benito, M., Polo, A., Gonzalez, B., Fernandez-Lobato, M. and Sanz-Aparicio, J. (2010) Structural and kinetic analysis of Schwanniomyces occidentalis invertase reveals a new oligomerization pattern and the role of its supplementary domain in substrate binding. J. Biol. Chem. 285, 13930-13941.

Banks, J.L., Beard, H.S., Cao, Y. et al. (2005) Integrated modeling program, applied chemical theory (IMPACT). J. Comput. Chem. 26, 1752-1780.

Beitz, E. (2000) $T_{E} X$ shade: shading and labeling of multiple sequence alignments using $L A T_{E} X 2_{\varepsilon}$. Bioinformatics, 16, 135-139.

Bujacz, A., Jedrzejczak-Krzepkowska, M., Bielecki, S., Redzynia, I. and Bujacz, G. (2011) Crystal structures of the apo form of $\beta$-fructofuranosidase from Bifidobacterium longum and its complex with fructose. FEBS J. 278, 17281744.

Chambert, R. and Petit-Glatron, M.F. (1991) Polymerase and hydrolase activities of Bacillus subtilis levansucrase can be separately modulated by site-directed mutagenesis. Biochem. J. 279, 35-41.

Chuankhayan, P., Hsieh, C.Y., Huang, Y.C., Hsieh, Y.Y., Guan, H.H., Hsieh, Y.C., Tien, Y.C., Chen, C.D., Chiang, C.M. and Chen, C.J. (2010) Crystal structures of Aspergillus japonicus fructosyltransferase complex with donor/acceptor substrates reveal complete subsites in the active site for catalysis. J. Biol. Chem. 285, 23251-23264.

Collaborative Computational Project Number 4 (1994) The CCP4 suite: programs for protein crystallography. Acta Crystallogr. D 50, 760-763.

Davies, G.J., Wilson, K.S. and Henrissat, B. (1997) Nomenclature for sugarbinding subsites in glycosyl hydrolases. Biochem. J. 321, 557-559. 
Davis, I.W., Murray, L.W., Richardson, J.S. and Richardson, D.C. (2004) MolProbity: structure validation and all-atom contact analysis for nucleic acids and their complexes. Nucleic Acids Res. 32, W615-W619.

Duchateau, N., Bortlik, K., Simmen, U., Wiemken, A. and Bancal, P. (1995) Sucrose-fructan 6-fructosyltransferase, a key enzyme for diverting carbon from sucrose to fructan in barley leaves. Plant Physiol. 107, 1249-1255.

Edelman, J. and Jefford, T.G. (1968) The mechanism of fructosan metabolism in higher plants as exemplified in Helianthus tuberosus. New Phytol. 67 517-531.

Emsley, P. and Cowtan, K. (2004) Coot: model-building tools for molecular graphics. Acta Crystallogr. D 60, 2126-2132.

Evans, P. (2006) Scaling and assessment of data quality. Acta Crystallogr. D $62,72-82$.

Friesner, R.A., Banks, J.L., Murphy, R.B. et al. (2004) Glide: a new approach for rapid, accurate docking and scoring. 1. Method and assessment of docking accuracy. J. Med. Chem. 47, 1739-1749.

Friesner, R.A., Murphy, R.B., Repasky, M.P., Frye, L.L., Greenwood, J.R. Halgren, T.A., Sanschagrin, P.C. and Mainz, D.T. (2006) Extra precision glide: docking and scoring incorporating a model of hydrophobic enclosure for protein-ligand complexes. J. Med. Chem. 49, 6177-6196.

Gille, C. and Frommel, C. (2001) STRAP: editor for structural alignments of proteins. Bioinformatics, 17, 377-378.

Goldman, D., Lavid, N., Schwartz, A., Shoham, G., Danino, D. and Shoham, Y (2008) Two active forms of Zymomonas mobilis levansucrase: an ordered microfibril structure of the enzyme promotes levan polymerization. J. Biol. Chem. 283, 32209-32217.

Hendry, G.A.F. (1993) Evolutionary origins and natural functions of fructans a climatological, biogeographic and mechanistic appraisal. New Phytol. 123, 3-14.

Hothorn, M., Van den Ende, W., Lammens, W., Rybin, V. and Scheffzek, K. (2010) Structural insights into the $\mathrm{pH}$-controlled targeting of plant cell-wall invertase by a specific inhibitor protein. Proc. Natl Acad. Sci. U.S.A. 107 17427-17432.

Hutchinson, E.G. and Thornton, J.M. (1996) PROMOTIF - a program to identify and analyze structural motifs in proteins. Protein Sci. 5, 212-220.

Johansson, P., Brumer, H. 3rd, Baumann, M.J., Kallas, A.M., Henriksson, H., Denman, S.E., Teeri, T.T. and Jones, T.A. (2004) Crystal structures of a poplar xyloglucan endotransglycosylase reveal details of transglycosylation acceptor binding. Plant Cell, 16, 874-886.

Kabsch, W. (1993) Automatic processing of rotation diffraction data from crystals of initially unknown symmetry and cell constants. J. Appl. Crys tallogr. 26, 795-800.

Krissinel, E. and Henrick, K. (2007) Inference of macromolecular assemblies from crystalline state. J. Mol. Biol. 372, 774-797.

Lammens, W., Le Roy, K., Van Laere, A., Rabijns, A. and Van den Ende, W. (2008) Crystal structures of Arabidopsis thaliana cell-wall invertase mutants in complex with sucrose. J. Mol. Biol. 377, 378-385.

Lammens, W., Le Roy, K., Schroeven, L., Van Laere, A., Rabijns, A. and Van den Ende, W. (2009) Structural insights into glycoside hydrolase family 32 and 68 enzymes: functional implications. J. Exp. Bot. 60, 727-740.

Laskowski, R.A. (2001) PDBsum: summaries and analyses of PDB structures. Nucleic Acids Res. 29, 221-222.

Laskowski, R.A. (2009) PDBsum new things. Nucleic Acids Res. 37, D355D359.

Lasseur, B., Schroeven, L., Lammens, W., Le Roy, K., Spangenberg, G. Manduzio, H., Vergauwen, R., Lothier, J., Prud'homme, M.P. and Van den Ende, W. (2009) Transforming a fructan:fructan 6G-fructosyltransferase from perennial ryegrass into a sucrose:sucrose 1-fructosyltransferase. Plant Physiol. 149, 327-339.

Lasseur, B., Lothier, J., Wiemken, A., Van Laere, A., Morvan-Bertrand, A., Van den Ende, W. and Prud'homme, M.-P. (2011) Towards a better understanding of the generation of fructan structure diversity in plants: molecular and functional characterization of a sucrose:fructan 6-fructosyltransferase (6-SFT) cDNA from perennial ryegrass (Lolium perenne). J. Exp. Bot. 62, 1871-1885.

Le Roy, K., Lammens, W., Verhaest, M., De Coninck, B., Rabijns, A., Van Laere, A. and Van den Ende, W. (2007) Unraveling the difference between invertases and fructan exohydrolases: a single amino acid (Asp239) substitution transforms Arabidopsis cell-wall invertase 1 into a fructan 1-exohydrolase. Plant Physiol. 145, 616-625.
Le Roy, K., Lammens, W., Van Laere, A. and Van den Ende, W. (2008) Influencing the binding configuration of sucrose in the active sites of chicory 1-FEH Ila and sugar beet 6-FEH. New Phytol. 178, 572-580.

Lerouge, P., Cabanes-Macheteau, M., Rayon, C., Fischette-Laine, A.C., Gomord, V. and Faye, L. (1998) N-glycoprotein biosynthesis in plants: recent developments and future trends. Plant Mol. Biol. 38, 31-48.

Leslie, A.G. (2006) The integration of macromolecular diffraction data. Acta Crystallogr. D 62, 48-57.

Li, S.Y., Chen, M., Li, G., Yan, Y.L., Yu, H.Y., Zhan, Y.H., Peng, Z.X., Wang, J. and Lin, M. (2008) Amino acid substitutions of His296 alter the catalytic properties of Zymomonas mobilis 10232 levansucrase. Acta Biochim. Pol. 55, 201-206.

Murshudov, G.N., Vagin, A.A. and Dodson, E.J. (1997) Refinement of macromolecular structures by the maximum-likelihood method. Acta Crystallogr. D 53, 240-255.

Nishizawa, A., Yabuta, Y. and Shigeoka, S. (2008) Galactinol and raffinose as a novel function to protect plants from oxidative damage. Plant Physiol. 147, 1251-1263.

Otwinowski, Z. and Minor, W. (1997) Processing of X-ray diffraction data collected in oscillation mode. Methods Enzymol. 276, 307-326.

Paoli, M. (2001) Protein folds propelled by diversity. Prog. Biophys. Mol. Biol. 76, 103-130.

Pijning, T., Anwar, M.A., Boger, M., Dobruchowska, J.M., Leemhuis, H., Kralj, S., Dijkhuizen, L. and Dijkstra, B.W. (2011) Crystal structure of inulosucrase from Lactobacillus: insights into the substrate specificity and product specificity of GH68 fructansucrases. J. Mol. Biol. 412, 80-93.

Prud'homme, M.P., Morvan-Bertrand, A., Lasseur, B., Lothier, J., Meuriot, F., Decau, M.L. and Noiraud-Romy, N. (2007) Lolium perenne, backbone of sustainable development, source of fructans for grazing animals and potential source of novel enzymes. In Recent Advances in Fructooligosac charides Research (Shiomi, N., Benkeblia, N. and Onodera, S., eds). Kerala India: Research Signpost, pp. 231-258.

Ritsema, T., Hernandez, L., Verhaar, A., Altenbach, D., Boller, T., Wiemken, A and Smeekens, S. (2006) Developing fructan-synthesizing capability in a plant invertase via mutations in the sucrose-binding box. Plant J. 48, 228-237.

Schroeven, L., Lammens, W., Van Laere, A. and Van den Ende, W. (2008) Transforming wheat vacuolar invertase into a high affinity sucrose:sucrose 1-fructosyltransferase. New Phytol. 180, 822-831.

Schroeven, L., Lammens, W., Kawakami, A., Yoshida, M., Van Laere, A. and Van den Ende, W. (2009) Creating S-type characteristics in the F-type enzyme fructan:fructan 1-fructosyltransferase of Triticum aestivum L. J. Exp. Bot. 60, 3687-3696.

Sonnenburg, E.D., Zheng, H., Joglekar, P., Higginbottom, S.K., Firbank, S.J. Bolam, D.N. and Sonnenburg, J.L. (2010) Specificity of polysaccharide use in intestinal Bacteroides species determines diet-induced microbiota alterations. Cell, 141, 1241-1252.

Stoyanova, S., Geuns, J., Hideg, E. and Van den Ende, W. (2011) The food additives inulin and stevioside counteract oxidative stress. Int. J. Food Sci. Nutr. 62, 207-214.

Tamura, K., Kawakami, A., Sanada, Y., Tase, K., Komatsu, T. and Yoshida, M. (2009) Cloning and functional analysis of a fructosyltransferase cDNA for synthesis of highly polymerized levans in timothy (Phleum pratense L.). J. Exp. Bot. 60, 893-905.

Vagin, A. and Teplyakov, A. (1997) MOLREP: an automated program for molecular replacement. J. Appl. Crystallogr. 30, 1022-1025.

Vaguine, A.A., Richelle, J. and Wodak, S.J. (1999) SFCHECK: a unified set of procedures for evaluating the quality of macromolecular structure-factor data and their agreement with the atomic model. Acta Crystallogr. D 55, 191-205.

Valluru, R. and Van den Ende, W. (2008) Plant fructans in stress environments: emerging concepts and future prospects. J. Exp. Bot. 59, 2905-2916.

Van den Ende, W. and Valluru, R. (2009) Sucrose, sucrosyl oligosaccharides, and oxidative stress: scavenging and salvaging? J. Exp. Bot. 60, 9-18.

Van den Ende, W. and Van Laere, A. (2007) Fructans in dicotyledonous plants: occurrence and metabolism. In Recent Advances in Fructooligosaccharides Research (Shiomi, N., Benkeblia, N. and Onodera, S., eds). Kerala, India: Research Signpost, pp. 1-14.

Van den Ende, W., Van Laere, A., Le Roy, K., Vergauwen, R., Boogaerts, D. Figueiredo-Ribeiro, R.C.L. and Machado de Carvalho, M.A. (2005) Molecular cloning and characterization of a high DP fructan:fructan 1-fructosyl 
transferase from Viguiera discolor (Asteraceae) and its heterologous expression in Pichia pastoris. Physiol. Plant. 125, 419-429.

Van den Ende, W., Clerens, S., Vergauwen, R., Boogaerts, D., Le Roy, K., Arckens, L. and Van Laere, A. (2006) Cloning and functional analysis of a high DP fructan:fructan 1-fructosyl transferase from Echinops ritro (Asteraceae): comparison of the native and recombinant enzymes. J. Exp. Bot.57, 775-789.

Van den Ende, W., Lammens, W., Van Laere, A., Schroeven, L. and Le Roy, K. (2009) Donor and acceptor substrate selectivity among plant glycoside hydrolase family 32 enzymes. FEBS J. 276, 5788-5798.

Van den Ende, W., Coopman, M., Clerens, S., Vergauwen, R., Le Roy, K., Lammens, W. and Van Laere, A. (2011a) Unexpected presence of graminan- and levan-type fructans in the evergreen frost-hardy eudicot Pachysandra terminalis (Buxaceae). Purification, cloning and functional analysis of a 6-SST/6-SFT enzyme. Plant Physiol. 155, 603-614.

Van den Ende, W., Peshev, D. and De Gara, L. (2011b) Disease prevention by natural antioxidants and prebiotics acting as ROS scavengers in the gastrointestinal tract. Trends Food Sci. Technol. 22, 689-697.

Vereyken, I.J., Chupin, V., Islamov, A., Kuklin, A., Hincha, D.K. and de Kruijff, B. (2003) The effect of fructan on the phospholipid organization in the dry state. Biophys. J. 85, 3058-3065.

Vergauwen, R., Van Laere, A. and Van den Ende, W. (2003) Properties of fructan:fructan 1-fructosyltransferases from Cichorium intybus L. and Echinops ritro L., two asteracean plants storing greatly different types of inulin. Plant Physiol. 133, 391-401.
Verhaest, M., Van den Ende, W., Le Roy, K., De Ranter, C.J., Van Laere, A. and Rabijns, A. (2005) X-ray diffraction structure of a plant glycosyl hydrolase family 32 protein: fructan 1-exohydrolase lla of Cichorium intybus. Plant J. 41, 400-411.

Verhaest, M., Lammens, W., Le Roy, K., De Coninck, B., De Ranter, C.J., Van Laere, A., Van den Ende, W. and Rabijns, A. (2006) X-ray diffraction structure of a cell-wall invertase from Arabidopsis thaliana. Acta Crystallogr. D 62, 1555-1563.

Verhaest, M., Lammens, W., Le Roy, K., De Ranter, C.J., Van Laere, A., Rabijns A. and Van den Ende, W. (2007) Insights into the fine architecture of the active site of chicory fructan 1-exohydrolase: 1-kestose as substrate vs sucrose as inhibitor. New Phytol. 174, 90-100.

Vijn, I. and Smeekens, S. (1999) Fructan: more than a reserve carbohydrate? Plant Physiol. 120, 351-359.

Wei, J.Z. and Chatterton, N.J. (2001) Fructan biosynthesis and fructosyltransferase evolution: expression of the 6-SFT (sucrose:fructan 6-fructosyltransferase) gene in crested wheatgrass (Agropyron cristatum). J. Plant Physiol. 158, 1203-1213.

Yanase, H., Maeda, M., Hagiwara, E., Yagi, H., Taniguchi, K. and Okamoto, K. (2002) Identification of functionally important amino acid residues in Zymomonas mobilis levansucrase. J. Biochem. 132, 565-572.

Yoshida, M., Kawakami, A. and Van den Ende, W. (2007) Graminan metabolism in cereals: wheat as a model system. In Recent Advances in Fruc tooligosaccharides Research (Shiomi, N., Benkeblia, N. and Onodera, S., eds). Kerala, India: Research Signpost, pp. 201-212. 